\title{
A Solid Oxide Fuel Cell Micro - Scale Modeling with Spherical Particle Shaped Electrodes
}

\author{
P. Chinda ${ }^{1, *}$, S. Chanchaona ${ }^{1}$, P. Brault ${ }^{2}$ and W. Wechsatol ${ }^{1, *}$ \\ ${ }^{1}$ Department of Mechanical Engineering, King Mongkut's University of Technology Thonburi, \\ 126 Pracha-utid Road, Bangmod, Thungkru, Bangkok, 10140, Thailand \\ ${ }^{2}$ Groupe de Recherche sur l'énergétique des Milieux Ionisés (GREMI), \\ UMR 6606 CNRS-Université d'Orléans, BP6744, 45067, Orléans Cedex 2, France \\ *Corresponding author: wishsanuruk.wec@kmutt.ac.th ; penyarat@yahoo.com
}

\begin{abstract}
A micro - scale model of a Solid Oxide Fuel Cell (SOFC) involving the mass transfer together with the electrochemical reaction, the electron and ion transports through the respective spherically shaped electron and ion conducting particles inside the electrodes was mathematically developed. Couples of useful dimensionless parameters were introduced in order to represent the characteristics of the cell. The predicted cell performance was showed according to various operating and design conditions. The effects of micro - scale electrode geometry on the cell performance were also taken into account. Parametric study according to the volumetric fraction of ionic and electronic conducting particles was conducted in order to examine the effects of operating conditions on the cell overpotentials. The study results substantiate the fact that SOFC overpotential could be effectively decreased by increasing the operating temperature as well as operating pressure. This present study reveals the working mechanisms of SOFC at the micro - scale level, while demonstrating the use of micro - scale relations to enhance the SOFC performance. The accuracy of the presented model was validated by comparing to already existing experimental results from the available literatures.
\end{abstract}

Keywords: cell overpotential ; dimensionless parameter ; electrochemical reaction ; mass transfer ; volumetric fractions of ionic/electronic

\section{Introduction}

The solid oxide fuel cell (SOFC) is a highly efficient energy conversion system that transforms chemical energy to electrical energy and heat directly from gasified fuels by electrochemical reactions 
of fuels and oxidants. The supplied fuels can be hydrocarbon compounds such as $\mathrm{CH}_{4}, \mathrm{C}_{2} \mathrm{H}_{6}$ and $\mathrm{C}_{3} \mathrm{H}_{8}$, as well as $\mathrm{CO}$ beside $\mathrm{H}_{2}$. The SOFC can be applied to versatile power generation systems, either stationary power generators or auxiliary power sources in automobiles, in aircrafts or even in residential applications [1, 2]. Many researchers have been focused focusing on developing the SOFC fabrication techniques, and new materials to make the SOFC possible commercial applications. Ramakrishna et al. [3] performed numerical analyses of a SOFC on a CFD - ACE package and proposed an innovative thin - walled geometry to improve the power density of the cell. Recently, a novel 3-D SOFC was developed by Koh et al. [4] to increase the volumetric power density by increasing the volumetric surface areas of the electrodes., Yang et al. [5] and Hwang et al. [6,7] developed a numerical model to investigate the characteristics of a mono - block - layer built SOFC (MOLB - SOFC), and found that the MOLB - SOFC provides higher fuel/oxidant utilization than the planar type SOFC. The higher utilization of the fuel and oxidant reflects the higher current generated by the SOFC. However, the current density distributions are less uniform in MOLB - SOFC, which is a significant disadvantage. The major limitation of SOFC usage is their high operating temperature. Intermediate temperature SOFCs and low temperature SOFCs become the subject of interest to lower the operating temperature as well as the material cost of SOFCs. The techniques of thin electrolyte and electrode coating involving new materials have made the creation of intermediate and low temperature SOFCs possible. Yttria - Stabilized Zirconia (YSZ), which is normally used to produce cell electrolytes operating at a high temperature, can still be used in intermediate and low temperature SOFCs. Many studies on Ceria as a possible material for fabricating electrolyte are widely conducted by many researchers $[8-11]$. B. The thin film deposition, a technique widely used for decades in fabrication of Proton Exchange Membrane Fuel Cells (PEMFCs) [12] is now applied in SOFC fabrication [13 - 15]. One of the main advantages of such a thin film fuel cell is that its ohmic resistance is low enough to maintain its high performance at low operating temperature.

In an analysis of the SOFC system, computer simulation based on theoretical modeling is known to be an efficient method to predict the cell, stack or system performance. Mathematical models that predict performance can aid in understanding and development of SOFCs. A mathematical simulation of a SOFC is helpful in examining parametric issues such as temperatures, materials, geometries, dimensions, fuels, and fuel reformation and in determining their associated performance characteristics. Moreover, the mathematical model is an important tool in design 
optimization and helpful to answer important practical questions such as appropriate air and fuel flow rates required to avoid excessive temperature or pressure drop. With the ability to provide answers for specific questions various modeling approaches exist. The modeling may focus on individual thermalmechanical, flow, chemical, and electrochemical subsystems or on coupled integrated systems. Because the subsystems are typically characterized by different length scales, modeling may also take place on different levels, ranging from the system level, the cell stack level or the single cell level. The viewpoint of single cell level modeling is divided into macroscopic modeling and microscopic modeling. The macroscopic modeling examines the cell behavior based on the viewpoint of fluid, heat and mass transports. The effects of porosity on reactant concentration and ohmic overpotentials could also be considered in the macroscopic modeling. The macroscopic appearances of electrodes such as tortuosity and porosity are also related to the microscopic arrangement of electrode particles. However, the activation overpotential was being treated as a property independent of the porosity, while the electrochemical reactions was assumed to occur merely at the interface between electrode and electrolyte layers. Thus macroscopic modeling can hardly predict the effects of electrode structure on the chemical reaction within SOFCs; thus it is insufficient to investigate precisely the microstructural effects. Microscopic modeling considering the influence of the electrode structures on the electrochemical reaction at the three phase boundary (TPB) has recently been proposed. The microscopic modeling has been applied to SOFC study during the recent years and has offered possibilities to enhance the SOFC performance [16-25].

Literature reviews showed that the electrode microscopic model of SOFCs can roughly be divided into pore model [16] random resistor network model [17-19] and random packing sphere model [20]. In the pore model, the ionic conductor in the electrode is viewed as protruding from the dense electrolyte surface with electronic conductor particles spread over the surface in a connected network and the remaining space is filled by continuous pore structure for the transport of gases. In the random resistor network model, the electrode is assumed to consist of grains of the electronic conductors and the ionic conductors packed together so as to form a continuous network. In the random packing sphere model, the electrode is assumed to be random packing of spheres. The theory of the particle coordination number was applied, together with percolation theory. The application of the random packing sphere model on the microscopic SOFCs modeling are shown below as, 
Costamagna et al. [20] is the first to develop a microscopic model of SOFC with random packing sphere electrode model. The model is for the evaluation of the performance of an electrode formed by a mixture of electronic conductor and ionic conductor with nearly spherical particle shape. The results of the mode1 show that the effects of morphology, i.e. the volumetric composition of the electrode and the dimensions of the particles, strongly influent the electrode resistance. The model has been applied to EDB/Pt and YSZ/LSM cathodes and YSZ/Ni anodes. However, in these models, the complex gas transport phenomena in the electrode were ignored, despite its importance. Although concentration overpotential does not play an important role in most cases especially for thin anode, it does somehow affect the fuel cell performance significantly if crucial parameters related to microstructure of the anode are not well chosen. Chen et al. [21] were applied the electrode microscopic model with random packing sphere theory to develop a mechanistic model for oxygen reduction at YSZ/LSM interface. A complete microscopic model for YSZ/LSM composite cathode considering all forms of over-potentials was developed and established the interrelationship among the transport phenomena, electrochemical processes and the microstructure of the composite cathode. The exchange current densities of the rate-limiting steps used in the simulation and the model can be used as a tool to guide the design for better cathodes. Deseure et al. [22] developed a microscopic model for a composite cathode similar to Chen et al. [21]. Simulation was conducted to predict the optimal design parameters, i.e. cathode thickness, particle size, particle size ratio and YSZ volume fraction for a LSM/YSZ composite cathode. Hussain et al. [23] were applied the electrode microscopic model with random packing sphere theory to consider on an anode-supported planar SOFC with thin layer reaction zone in the vicinity of electrolyte. Their numerical results have shown that the increase of either porosity or tortuosity of electrodes leads to worse cell performance, while better cell performance is obtained when the volume fraction of electronic conducting particles is approximately equal to that of ionic conducting particles in reaction zone. Recently they extended their investigation to the cell design with two distinct layers of an anode electrode, i.e. reaction layer and backing layer. Ni et al. [24] were applied the electrode microscopic model with random packing sphere theory to develop a mathematical model for modeling the performance of solid oxide fuel cell (SOFC) with functionally graded electrodes at the micro-scale level. The model considered all forms of overpotentials and was able to capture the coupled electrochemical reactions and mass transport involved in the SOFC operation. Additional modeling analyses were conducted to gain better 
understanding of the SOFC working mechanisms at the micro-scale level and to quantify the performance of micro-structurally graded SOFC. Micro-structural grading could significantly enhance the gas transport but had negligible effects on the ohmic and activation overpotentials, especially for thick electrodes. Hussain et al. [25] were applied the electrode microscopic model with random packing sphere theory to consider on an anode-supported planar SOFC with thin layer reaction zone in the vicinity of electrolyte. A simulation is conducted using the developed mathematical model, where in an SOFC electrode is considered as a porous composite structure of electron- and ion-conducting particles. An electrode is treated as a reaction zone layer having triple phase boundaries (TPBs) scattered throughout the electrode, consistent with the micro modeling approach of treating electrodes. The model takes into account the transport of multi-component mixture in an electrode together with electrochemical reaction. In their works are considered the governing equations in the form of nondimensionalized.

Unlike other previous researches, the effect of electrodes' microscopic geometry on the cell performance of an anode - supported Solid Oxide Fuel Cell is included in the microscopic scale modeling. In this study, the microscopic model of an SOFC porous electrode that formed by mixture of electronic conductor and ionic conductor was developed. The mathematical model is based on the assumption that the electrodes were formed by spherical-shaped particles with the random packing sphere model [20] and takes into account electronic, ionic, and gas transport together with the electrochemical reaction. The forms of overpotentials losses are considered with the intention to maximize the SOFC performance by optimally design the microstructure of SOFC electrodes. In this work are also considered the governing equations in the form of non-dimensionalized.

\section{Cell geometry and the assumptions of the model}

\subsection{Cell geometry}

An illustration of physical domain of the SOFC is shown in Fig. 1. Fig.1 (a) shows the structure of a unit cell with multiple channels whereas Fig.1 (b) shows the cross-sectional representation of a composite anode. The computational domain is shown in Fig.1 (b), which includes the land portion of the interconnect (current collector) interfacing the anode, the porous portion of the anode interfacing the flow channel, the anode and another is interface to an electrolyte. 


\subsection{The assumptions of the model}

The cell is assumed to operate under steady state and to assume that the parameters vary only in the vertical direction, as shown in Fig. 1 (b). The temperature is uniform throughout the anode. The convective flux is negligible in the porous anode when compared to the diffusive flux of gaseous species, which means the primary mode of species transport in the porous anode is by diffusion. The reactant gas mixtures are approximated as ideal gases with negligible Soret, Dofour and gravity effects. The anode is a composite porous structure, it is modeled based on the assumption that the composite electrode is represented by the particles of randomly packed electron - and ion conducting particles and disregards the actual geometric details of the individual particles, according to Costamagna [20].

The useful dimensionless parameters were introduced in order to represent the characteristic of the cell. From the Fig. 1, geometrical dimensionless parameters that relate with the cell geometry and particle sizes can be defined as follows;

$$
\tilde{x}_{a}=\frac{x_{a}}{t_{a n}}, \quad \tilde{x}_{c}=\frac{x_{c}}{t_{c a t}}, \quad \tilde{r}=\frac{r}{\left(V_{0}\right)^{1 / 3}}, \quad \tilde{A}_{v}=\frac{A_{v}}{\left(V_{0}\right)^{-1 / 3}}
$$

where $\tilde{x}_{a}$ and $\tilde{x}_{c}$ are dimensionless positions in the anode and cathode. $x_{a}$ and $x_{c}$ are positions in the anode and cathode (m), $t_{a n}$ and $t_{c a t}$ are the anode and cathode thickness (m), $\tilde{r}$ is the dimensionless particle radius, $r$ is the radius of spherical particles of the electrodes $(\mathrm{m})$ and $V_{0}$ is the reference spherical particle volume of electrode $\left(\mathrm{m}^{3}\right)$ based on reference particle radius $\left(r_{0}\right)$ which is shown in Table 2. $\widetilde{A}_{v}$ is the dimensionless active surface area per unit volume and $A_{v}$ is the active surface area per unit volume $\left(\mathrm{m}^{-1}\right)$. The parameter $A_{v}$ can be calculated with the method based on the particle coordination number in binary random packing of spheres proposed by Costamagna et al. [20],

$$
A_{v}=\pi \sin ^{2} \theta r_{e l}^{2} n_{t} n_{e l} n_{i o} \frac{Z_{e l} Z_{i o}}{Z} p_{e l} p_{i o}
$$

All above mentioned parameters required to calculate $A_{v}[20,21]$ related to each other as shown here;

$$
\begin{aligned}
& n_{e l}=\frac{\varphi}{\left[\varphi+\left((1-\varphi) /\left(r_{i o} / r_{e l}\right)^{3}\right)\right]} \quad \text { and } \quad n_{i o}=1-n_{e l} \\
& Z_{e l}=3+\frac{Z-3}{\left[n_{e l}+\left(1-n_{e l}\right)\left(r_{i o} / r_{e l}\right)^{2}\right]} \text { and } Z_{i o}=3+\frac{(Z-3)\left(r_{i o} / r_{e l}\right)^{2}}{\left[n_{e l}+\left(1-n_{e l}\right)\left(r_{i o} / r_{e l}\right)^{2}\right]} \\
& p_{e l}=\left[1-\left(4-Z_{e l-e l}\right)^{2.5}\right]^{0.4} \text { and } \quad p_{i o}=\left[1-\left(4-Z_{i o-i o}\right)^{2.5}\right]^{0.4}
\end{aligned}
$$




$$
\begin{aligned}
& Z_{e l-e l}=\frac{n_{e l} Z_{e l}^{2}}{Z} \quad \text { and } \quad Z_{i o-i o}=\frac{n_{i o} Z_{i o}^{2}}{Z} \\
& n_{t}=\frac{1-\varepsilon}{(4 / 3) \pi r_{e l}^{3}\left[n_{e l}+\left(1-n_{e l}\right)\left(r_{i o} / r_{e l}\right)^{3}\right]}
\end{aligned}
$$

$\theta$ being the contact angle between electron and ion conducting particle, $r_{e l}$ is the radius of the electron conducting particles, $n_{t}$ is the total number of particles per unit volume, $n_{e l}$ and $n_{i o}$ are the number of electron and ion conducting particles, $Z_{e l}$ and $Z_{i o}$ are the coordination number of electron and ion conducting particles. $Z$ is the total average particle coordination number in the electrode which is equal to 6 [20]. The $p_{e l}$ and $p_{i o}$ are the probabilities for an electron and an ion conducting particles that belong to the connecting ends of the electrode, respectively. $\varphi$ is a volumetric fraction of the electron conducing particle in an electrode, $Z_{e l-e l}$ represents the average coordination number between electronic particles and $Z_{i o-i o}$ represents the average coordination number between ionic particles [20,21]. In the present study, $r_{e l}$ is assumed equal to $r_{i o}$.

Another parameter that is depicted in Fig. 1(b), $\widetilde{N}_{i}$ is dimensionless diffusive fluxes of species $i$,

$$
\widetilde{N}_{i}=\frac{N_{i}}{\left(\frac{J_{\text {total }}}{n F}\right)}
$$

$J_{\text {total }} / n F$ is the molar flux of reactant species.$N_{i}$ is diffusive fluxes of species $i\left(\mathrm{~mol} \mathrm{~m}^{-2} \mathrm{~s}^{-1}\right) . J_{\text {total }}$ is the total current density drawn from the cell $\left(\mathrm{A} \mathrm{m}^{-2}\right), \mathrm{n}$ is the number of electrons participating in the electrochemical reaction that is equal to 2 and $F$ is the Faraday's constant $\left(96485 \mathrm{C} \mathrm{mol}^{-1}\right)$. With above assumptions, the model is formulated and described as follows.

\section{Modeling and dimensionless governing equations}

Porous composite electrodes are commonly used in fuel cells due to their extended zone for electrochemical reactions, thus improving the current output of an electrode. The performance of a porous electrode depends on, but is not limited to: (1) the activity of electro catalysts, (2) the specific surface area $\left(\mathrm{m}^{2} \mathrm{~m}^{-3}\right)$ available for electrochemical reaction, (3) the mass transport phenomena, and (4) the ionic and electronic conductivity of the electrode. Because of the complexity of mass transport, the ionic and electronic transport and electrochemical reaction, so a complicated simulation technique was employed to predict cell performance under various operating conditions, and for parametric study. The present model aims to optimize the SOFC performance by optimizing the microstructure 
relations of SOFC electrode by micro - scale modeling. This model is considered for optimization of the volumetric fraction of ionic and electronic conducting particles of the electrodes. For sake of simplicity, we assume that a particle radius of both ionic and electronic conducting particles is equal.

\subsection{Anode side modeling}

The configuration of a SOFC anode can be simply modeled as shown of Fig.1(b). In Fig.1(b), the gray spherical particles represent the ionic conducting particles that in this case are YSZ (Yttria Stabilized Zirconia) and the black spherical particles represent the electronic conducting particles that in this case is Nickel (Ni) contained inside the anode. The coupled electrochemical reaction and mass transfer in a composite anode as modeled by Fig.1(b) can be summarized as: (1) transport of reactant $\left(\mathrm{H}_{2}\right)$ to the reaction sites through the pores of the anode and transport of $\mathrm{O}^{2-}$ from the electrolyte to the reaction sites through the ionic conducting particles, (2) electrochemical reaction of $\mathrm{H}_{2}$ and $\mathrm{O}^{2-}$ to form $\mathrm{H}_{2} \mathrm{O}$ and electrons at the active sites, (3) transport of electrons from the active sites to the current collector through the electronic conducting particles and transport of the $\mathrm{H}_{2} \mathrm{O}$ product to the anode surface via the pores of the anode.

Charge balance in the electronic and ionic conducting particles can be written as;

and

$$
\begin{aligned}
& \nabla \cdot J_{e, a}=R_{a} \text { or } \nabla \cdot J_{e, a}=A_{v} J_{n, a} \\
& \nabla \cdot J_{i, a}=-R_{a} \text { or } \nabla \cdot J_{i, a}=-A_{v} J_{n, a}
\end{aligned}
$$

where $J_{e, a}$ and $J_{i, a}$ are the current density $\left(\mathrm{A} \mathrm{m}^{-2}\right)$ in the electronic and ionic conducting particles. $R_{a}$ is the volumetric current density produced in the anode due to hydrogen oxidation reaction $\left(\mathrm{A} \mathrm{m}^{-3}\right)$. $J_{n, a}$ is the transferred current per unit area of reactive surface $\left(\mathrm{A} \mathrm{m}^{-2}\right)$. According to Butler -Volmer equation $[22,23,25]$, the volumetric current density produced in the anode, $R_{a}$ can be determined from $[22,23,25]$;

$$
R_{a}=A_{v} J_{0, r e f}^{H_{2}}\left\{\left(\frac{c_{H 2}}{c_{H 2, r e f}}\right)^{\gamma_{H 2}}\left(\exp \left(\frac{\alpha z F \eta_{a}}{R T}\right)-\exp \left(-\frac{(1-\alpha) z F \eta_{a}}{R T}\right)\right)\right\}
$$

Equation (11) can be written in the dimensionless form;

$$
\begin{gathered}
\widetilde{R}_{a}=\left(\frac{c_{H_{2}}}{c_{H_{2}, r e f}}\right)^{\gamma_{H_{2}}}\left\{\exp \left(\alpha E_{1} \tilde{\eta}_{a}\right)-\exp \left(-(1-\alpha) E_{1} \tilde{\eta}_{a}\right)\right\} \\
\text { Or } \quad \widetilde{R}_{a}=\left(\frac{x_{H_{2}}}{x_{H_{2}, r e f}}\right)^{\gamma_{H_{2}}}\left(\frac{P}{P_{\text {ref }}}\right)^{\gamma_{H_{2}}}\left(\frac{T_{r e f}}{T}\right)^{\gamma_{H_{2}}}\left\{\exp \left(\alpha E_{1} \tilde{\eta}_{a}\right)-\exp \left(-(1-\alpha) E_{1} \tilde{\eta}_{a}\right)\right\}
\end{gathered}
$$


where $c_{\mathrm{H}_{2}}$ and $c_{\mathrm{H}_{2} \text {,ref }}$ are concentration and reference concentration of hydrogen $\left(\mathrm{mol} \mathrm{m} \mathrm{m}^{-3}\right.$ ), $x_{\mathrm{H}_{2}}$ and $x_{\mathrm{H}_{2}}$,ref are molar fraction and reference molar fraction of hydrogen, $T$ and $T_{\text {ref }}$ are temperature and reference temperature $(\mathrm{K}), P$ and $P_{r e f}$ are pressure and reference pressure $(\mathrm{Pa})$.

The dimensionless parameters in Eqs. (12) - (13) are defined below;

$$
\begin{array}{r}
\widetilde{R}_{a}=\frac{R_{a}}{A_{v} J_{0, r e f}^{H_{2}}} \\
\tilde{\eta}_{a}=\frac{\eta_{a}}{E_{r}}
\end{array}
$$

where $\tilde{\eta}_{a}$ is the dimensionless overpotential at the anode and $\eta_{a}$ is the overpotential at the anode (volt). $E_{l}=E_{r} /(R T / z F), \quad E_{r}$ is the reversible cell potential (Volt) that is obtained from Nernst's equation expressed by;

$$
E_{r}=-\frac{\Delta G^{o}}{2 F}-\frac{R T}{2 F} \ln \left(\frac{p_{H_{2} \mathrm{O}}^{a}}{p_{\mathrm{H}_{2}}^{a}\left(p_{\mathrm{O}_{2}}^{c}\right)^{1 / 2}}\right)=E^{o}+\frac{R T}{4 F} \ln \left(\frac{p_{\mathrm{O}_{2}}^{c}\left(p_{\mathrm{H}_{2}}^{a}\right)^{2}}{\left(p_{\mathrm{H}_{2} \mathrm{O}}^{a}\right)^{2}}\right)
$$

$\Delta G^{o}$ is the net standard Gibbs free energy of electrochemical reaction at 1 atm and $25{ }^{\circ} \mathrm{C}, E^{o}$ is the standard Nernst potential at $1 \mathrm{~atm}$ and $25^{\circ} \mathrm{C}, P_{\mathrm{H}_{2} \mathrm{O}}^{a}$ is the water partial pressure, $P_{\mathrm{H}_{2}}^{a}$ is the hydrogen partial pressure and $P_{O_{2}}^{c}$ is the oxygen partial pressure in the electrode. $J_{0, \text { ref }}$ is the reference exchange current densities at the reference concentration $c_{r e f}$ - i.e for $\mathrm{H}_{2}$ oxidation $J_{0, \text { ref }}^{\mathrm{H}_{2}}$ is $1320 \mathrm{~A} \mathrm{~m}^{-2}$ for $\mathrm{O}_{2}$ reduction $J_{0, \text { ref }}^{O_{2}}$ is $400 \mathrm{~A} \mathrm{~m}^{-2}$ [23]. $J_{0}^{r e f}$ is the reference exchange current density of the electrode i.e. for an anode, $J_{0, a}^{r e f}$ is $400 \mathrm{~A} \mathrm{~m}^{-2}$ and for a cathode, $J_{0, c}^{r e f}$ is $1300 \mathrm{~A} \mathrm{~m}^{-2}$ [23]. $P_{\mathrm{H}_{2} \mathrm{O}}$ and $P_{\mathrm{H}_{2} \mathrm{O}}^{0}$ are respectively the partial pressures of $\mathrm{H}_{2} \mathrm{O}$ within the porous anode and at the anode surface. Similarly, $P_{\mathrm{H}_{2}}$ and $P_{\mathrm{H}_{2}}^{0}$ are the partial pressures of $\mathrm{H}_{2}$ within the porous anode and at the anode surface. The parameter $\alpha$ is the charge transfer coefficient which is 0.5 [21], $z$ is the number of charges involved in a reaction. $R$ is universal gas constant equal to $8.314 \mathrm{Jmol}^{-1} \mathrm{~K}^{-1} . T$ is cell operating temperature $(\mathrm{K})$, $T_{r e f}$ is reference temperature that is equal to $298 \mathrm{~K}$ and $P_{r e f}$ is reference pressure that is equal to 1 atm. The $x_{H_{2}}$ is molar fraction of $\mathrm{H}_{2} . \eta_{a}$ is anode overpotential is defined as [23,25];

$$
\eta_{a}=\left(\phi_{i, a}-\phi_{e, a}\right)
$$

And the dimensionless anode overpotential $\left(\tilde{\eta}_{a}\right)$;

$$
\tilde{\eta}_{a}=\left(\tilde{\phi}_{i, a}-\tilde{\phi}_{e, a}\right)
$$

where $\tilde{\phi}_{i, a}=\frac{\phi_{i, a}}{E_{r}}$ and $\tilde{\phi}_{e, a}=\frac{\phi_{e, a}}{E_{r}}$ denote the dimensionless ionic and electronic potentials respectively. $\phi_{i, a}$ and $\phi_{e, a}$ denote the ionic and electronic potentials (V). The electronic and ionic 
potentials can be obtained from applying Ohm's law [20] as Eq. (19) and the dimensionless form is shown in Eq. (20).

$$
\begin{gathered}
\nabla \cdot \phi_{e, a}=-\rho_{e, a}^{e f f} J_{e, a} \text { and } \nabla \cdot \phi_{i, a}=-\rho_{i, a}^{e f f} J_{i, a} \\
\nabla \cdot \tilde{\phi}_{e, a}=-\tilde{J}_{e, a}\left(\frac{t_{a n} \cdot J_{0, a}^{r e f} \cdot \rho_{e, a}^{e f f}}{E_{r}}\right) \text { and } \nabla \cdot \tilde{\phi}_{i, a}=-\tilde{J}_{i, a}\left(\frac{t_{a n} \cdot J_{0, a}^{r e f} \cdot \rho_{i, a}^{e f f}}{E_{r}}\right)
\end{gathered}
$$

where $\rho^{\text {eff }}[23,25]$ is the effective resistivity $(\Omega \mathrm{m})$ and $J$ is the current density $\left(\mathrm{A} \mathrm{m}^{-2}\right)$. The subscripts $i$ and $e$ represent ionic and electronic conductors, respectively. $\rho^{\text {eff }}$ can be determined by Eq. (21) [23].

$$
\rho_{e, a}^{e f f}=\frac{\tau}{\varphi(1-\varepsilon) \sigma_{e, a}} \text { and } \quad \rho_{i, a}^{e f f}=\frac{\tau}{(1-\varphi)(1-\varepsilon) \sigma_{i, a}}
$$

where $\sigma_{e}$ is the conductivity of electronic conductor -i.e. for an anode, $\sigma_{e, a}$ is $2 \times 10^{6} \mathrm{~S} \mathrm{~m}^{-1}[20,26]$ and for a cathode, $\sigma_{e, c}$ is $1 \times 10^{4} \mathrm{~S} \mathrm{~m}^{-1}$ [27]. $\sigma_{i}$ is the ionic conductivity -i.e. for an anode $\sigma_{i, a}$ is $3.44 \times 10^{4} \exp (-10300 / T)$, for a cathode, $\sigma_{i, c}$ is also $3.44 \times 10^{4} \exp (-10300 / T)$ and $\tau$ is the electrode tortuosity. $\tau$ is found by applying a geometrical model for tortuosity of streamline in porous media when the particles have a spherical shape [28]. The relevant equations are shown in the appendix A.

The first and second derivatives of $\eta_{a}$ can be written as;

$$
\begin{gathered}
\frac{d \eta_{a}}{d x}=\rho_{e, a}^{e f f} J_{e, a}-\rho_{i, a}^{e f f} J_{i, a} \\
\frac{d^{2} \eta_{a}}{d x^{2}}=\rho_{e, a}^{e f f} \frac{d J_{e, a}}{d x}-\rho_{i, a}^{e f f} \frac{d J_{i, a}}{d x}=A_{v} R_{a} t_{a}\left(\rho_{e, a}^{e f f}+\rho_{i, a}^{e f f}\right)
\end{gathered}
$$

From Eq. (18) and Eq. (20), the first derivatives of $\tilde{\eta}_{a}$ can be written as;

$$
\frac{d \tilde{\eta}_{a}}{d \tilde{x}}=\widetilde{J}_{e, a} E_{2,1}-\widetilde{J}_{i, a} E_{2,2}
$$

And the second first derivatives of $\tilde{\eta}_{a}$ can be written as;

$$
\frac{d^{2} \tilde{\eta}_{a}}{d \tilde{x}^{2}}=\widetilde{R}_{a}\left[\frac{A_{v} J_{0, r e f}^{H_{2}}\left(t_{a n}\right)^{2}}{E_{r}}\left(\rho_{e, a}^{e f f}+\rho_{i, a}^{e f f}\right)\right]
$$

where $E_{2,1}=\left(t_{a n} J_{0, a}^{r e f} \rho_{e, a}^{\text {eff }}\right) / E_{r}$ and $E_{2,2}=\left(t_{a n} J_{0, a}^{r e f} \rho_{i, a}^{e f f}\right) / E_{r}$. At the anode surface $\widetilde{J}_{i, a}=0$ and $\widetilde{J}_{e, a}=\widetilde{J}_{\text {total }}=1$. At the electrolyte interface, $\widetilde{J}_{i, a}=\widetilde{J}_{\text {total }}=1$ and $\widetilde{J}_{e, a}=0$. The terms $J_{i, a}$ and $J_{e, a}$ are the anode ionic and electronic current density $\left(\mathrm{A} \mathrm{m}^{-2}\right)$ and $\widetilde{J}_{i, a}$ and $\widetilde{J}_{e, a}$ are the 
dimensionless ionic and electronic current densities, $\widetilde{J}_{i, a}=J_{i, a} / J_{\text {total }}$ and $\widetilde{J}_{e, a}=J_{e, a} / J_{\text {total }}$, $J_{\text {total }}$ is the total current density drawn from the cell $\left(\mathrm{A} \mathrm{m}^{-2}\right) . \quad \rho_{i, a}^{e f f}$ and $\rho_{e, a}^{e f f}$ are described above and show as Eq.(21).

The two boundary conditions for the second order differential Eq. (25) can be written as,

$$
\tilde{x}=0,\left.\frac{d \tilde{\eta}_{a}}{d \tilde{x}}\right|_{\tilde{x}=0}=\left(-\rho_{e, a}^{\text {eff }} J_{\text {total }}\right) \frac{t_{a n}}{E_{r}} \text { and } \tilde{x}=1,\left.\frac{d \tilde{\eta}_{a}}{d \tilde{x}}\right|_{\tilde{x}=1}=\left(\rho_{i, a}^{\text {eff }} J_{\text {total }}\right)\left(\frac{t_{a n}}{E_{r}}\right)
$$

While the electrochemical reactions due to mass transport occur in SOFC electrodes. Mass transport through a porous medium can be determined using concepts described by Krishna et al. [29]. For a single component, the mass transport equation can be written as;

$$
\frac{\varepsilon}{R T} \frac{\partial\left(y_{i} P\right)}{\partial t}=-\nabla \cdot N_{i}+r_{i} \quad\left(m o l m^{-3} s^{-1}\right)
$$

where $\varepsilon$ and $N_{i}$ represent the porosity and the rate of mass transport (or denotes as the molar flux of each species, $\mathrm{mol} \mathrm{m}^{-2} \mathrm{~s}^{-1}$ ), respectively, into porous media. $r_{i}$ is the rate of reaction inside the porous medium. The term on the left-hand side is valid when an unsteady state is approached. The first and second terms on the right-hand side represent the diffusion rate and the rate of reaction inside the porous medium. It was assumed earlier that the diffusion process is at a steady state and that the electrochemical reactions take place at the three phase boundary (TPB) inside the electrode. Therefore, within the thick anode, the first and second term on the right-hand side is significant, therefore Eq. (27) becomes

$$
\nabla \cdot N_{i}=r_{i}
$$

Equation (28) can be written in the form of dimensionless as Eq. (29).

$$
\nabla \cdot \widetilde{N}_{i}=\frac{r_{i} t_{a n}}{\left(\frac{J_{\text {total }}}{n F}\right)}
$$

where, again $N_{i}$ denotes the molar flux for each specie $\left(\mathrm{mol} \mathrm{m} \mathrm{m}^{-2} \mathrm{~s}^{-1}\right.$ ), and $\mathrm{r}_{\mathrm{i}}$ represents the rate of electrochemical reaction per unit volume of the porous electrode $\left(\mathrm{mol} \mathrm{m}^{-3} \mathrm{~s}^{-1}\right)$. The electrochemical reaction rate of $\mathrm{H}_{2} \mathrm{O}$ and $\mathrm{H}_{2}$ can be expressed by Faraday's Law as $r_{H_{2}}=\left(-A_{v} J_{n, a}\right) /(n F)$ and $r_{\mathrm{H}_{2} \mathrm{O}}=\left(A_{v} J_{n, a}\right) /(n F)$.

The rate of mass transport, $N_{i}$, generally depends on the operating conditions (reactant concentration, temperature and pressure) and the microstructure of the material (porosity, tortuosity 
and pore size). Three models were used to develop expressions for $N_{i}$ : the Fick, the Dusty-Gas and the Stefan-Maxwell models. Only, Fick Model (FM) and Dusty-Gas Model (DGM) are used to describe the transport of components within porous media but the Stefan-Maxwell Model (SMM) is a well-known mass transport model applied to nonporous medium [30]. The simplest model to describe transport of components through the gas phase within porous media is the Fick Model (FM), which describes the transport as a product of a diffusion coefficient and the partial - pressure gradient of the particular component [31]. Another model to describe the transport of components within porous media is the Dusty-Gas Model (DGM) that includes the permeation flux and is applied to take into account the effect of total pressure gradient on mass transport. However, this study was done on the basic assumption that the total pressure is uniform over the entire depth of the porous electrode. Thus, the definite total pressure gradient term can be ignored. Consequently, only the diffusion flux is addressed for the DGM model, which means the primary mode of species transport in the porous electrode is by diffusion. The mass transfer process inside the porous electrode is by means of diffusion and was also selected by the reason that described above and by the recommendations in the literatures [30, 31-33].

Suwanwarangkul et al. [30] were concluded that the DGM is the most appropriate model to simulate gas transport phenomena inside a SOFC thick electrode. The mass flux of species $\mathrm{i}$ can be determined by the DGM which is considered to be both Knudsen diffusion and Molecular diffusion. The DGM is the most suitable model for the $\mathrm{H}_{2}-\mathrm{H}_{2} \mathrm{O}$ system [30, 31]. Suwanwarangkul et al. [30] also demonstrated that only the DGM is recommended for a multi component system. This is because it takes into account Knudsen diffusion effect as well as Graham's law of diffusion to calculate the flux ratios. Thus the DGM was used to develop the expressions for $N_{i}$ in this work.

The DGM includes the Stefan-Maxwell formulation and takes into account Knudsen diffusion and Molecular diffusion [30]. Knudsen diffusion becomes significant when the mean-free path of the molecular species is much larger than the pore size, while Molecular diffusion is dominant for large pore sizes and high system pressures. It is assumed from this model that pore walls consist of giant molecules ('dust') uniformly distributed in space. These dust molecules are considered to be a dummy, or pseudo, species in the mixture. The general form of the DGM is shown in Eq. (30); 


$$
\frac{N_{i}}{D_{i, k}^{e f f}}+\sum_{j=1, j \neq i}^{n} \frac{y_{j} N_{i-} y_{i} N_{j}}{D_{i j}^{e f f}}=-\frac{1}{R T}\left(P \frac{d y_{i}}{d x}+y_{i} \frac{d P}{d x}\left(1+\frac{B_{0} P}{D_{i, k}^{e f f} \mu}\right)\right)
$$

where $x$ is a vertical direction, $y_{i}$ and $y_{j}$ are the molar fraction of species $i$ and $j . D_{i, k}^{e f f}$ is the effective Knudsen diffusion coefficient. For two binary component systems that the effective molecular diffusion coefficient $\left(D_{i m}^{e f f}\right)$ is considered as the effective binary diffusion coefficient $\left(D_{i j}^{e f f}\right)$.

Considering again on Eq. (30), the second term on the right-hand side of Eq. (30) is called the permeation flux and is applied to take into account the effect of total pressure gradient on mass transport. However, it is assumed in this study that the total pressure is uniform over the entire depth of the porous anode. Thus, the definite total pressure gradient term can be ignored. Consequently, only the diffusion flux is addressed such that Eq. (30) reduces to;

$$
\frac{N_{i}}{D_{i, k}^{e f f}}+\sum_{j=1, j \neq i}^{n} \frac{y_{j} N_{i}-y_{i} N_{j}}{D_{i j}^{e f f}}=-\frac{P}{R T} \frac{d y_{i}}{d x}
$$

For diffusion with heterogeneous chemical reactions, flux ratios are governed by reaction stoichiometry. Sum Eq. (31) over n species leads to Graham's law of diffusion in gas mixtures [29].

$$
\sum_{i=1}^{n} N_{i} \sqrt{M_{i}}=0
$$

where $M_{i}$ is molecular weight of component $i$. For two binary component systems $\left(\mathrm{H}_{2}(1)-\mathrm{H}_{2} \mathrm{O}(2)\right)$, Eq. (31) becomes;

$$
\frac{N_{\mathrm{H}_{2}}}{D_{i, k}^{e f f}}+\frac{y_{\mathrm{H}_{2} \mathrm{O}} N_{\mathrm{H}_{2}-} y_{\mathrm{H}_{2}} N_{\mathrm{H}_{2} \mathrm{O}}}{D_{\mathrm{H}_{2}-\mathrm{H}_{2} \mathrm{O}}^{\text {eff }}}=-\frac{P}{R T} \frac{d y_{\mathrm{H}_{2}}}{d x}
$$

Because $y_{\mathrm{H}_{2} \mathrm{O}}=1-y_{\mathrm{H}_{2}}$ and $N_{\mathrm{H}_{2} \mathrm{O}} / N_{\mathrm{H}_{2}}=-\sqrt{M_{\mathrm{H}_{2}} / M_{\mathrm{H}_{2} \mathrm{O}}}$ (Graham's law), $\alpha=1-\sqrt{M_{\mathrm{H}_{2}} / M_{\mathrm{H}_{2} \mathrm{O}}}$ , parameters $M_{\mathrm{H}_{2}}$ and $M_{\mathrm{H}_{2} \mathrm{O}}$ are molecular weight of $\mathrm{H}_{2}$ and $\mathrm{H}_{2} \mathrm{O}$. The $D_{\mathrm{H}_{2}, k}^{\text {eff }}$ and $D_{\mathrm{H}_{2}-\mathrm{H}_{2} \mathrm{O}}^{\text {eff }}$ are the effective Knudsen diffusion coefficient of $\mathrm{H}_{2}$ and the effective binary (molecular) diffusion coefficient of $\mathrm{H}_{2}-\mathrm{H}_{2} \mathrm{O}$ [35], respectively. The Knudsen diffusion coefficient $\left(D_{i, k}\right)$ and effective Knudsen diffusion coefficient ( $D_{i, k}^{e f f}$ ) for each gas specie [35] can be calculated by Eqs. (34) and (35).

$$
\begin{aligned}
D_{i, k} & =\frac{2}{3} \vec{r} \sqrt{\frac{8 R T}{\pi M_{i}}}=97.0 \vec{r} \sqrt{\frac{T}{M_{i}}} \\
D_{i, k}^{e f f} & =\left(\frac{\varepsilon}{\tau}\right) D_{i, k}
\end{aligned}
$$


The binary diffusion coefficient $\left(D_{i, j}\right)$ is calculated by using the Chapman-Enskog equation [35] which is recalled in appendix B. Similar to the effective Knudsen diffusion coefficient, the effective binary diffusion coefficient through the porous electrode can be calculated by Eq. (36).

$$
D_{i, j}^{e f f}=\left(\frac{\varepsilon}{\tau}\right) D_{i, j}
$$

From Eq.(33) that $N_{H_{2}}$ can be written as follows :

$$
N_{H_{2}}=-\frac{P}{R T}\left(\frac{1-\alpha y_{H_{2}}}{D_{H_{2} \mathrm{o}-H_{2}}^{e f f}}+\frac{1}{D_{H_{2}, k}^{e f f}}\right)^{-1} \frac{d y_{H_{2}}}{d x}
$$

The $N_{H_{2}}$ can be written in the dimensionless form as;

$$
\widetilde{N}_{H_{2}}=\left(-\frac{P}{R T}\left(\frac{1}{D_{H_{2}, k}^{e f f}}+\frac{1-\alpha y_{H_{2}}}{D_{H_{2}-H_{2} \mathrm{O}}^{e f f}}\right)^{-1} \frac{d y_{H_{2}}}{d x}\right) /\left(\frac{J_{\text {total }}}{n F}\right)=-\frac{P n F}{R T J_{\text {total }}}\left(\frac{1}{D_{H_{2}, k}^{e f f}}+\frac{1-\alpha y_{H_{2}}}{D_{H_{2}-H_{2} \mathrm{O}}^{e f f}}\right)^{-1} \frac{d y_{H_{2}}}{d x}
$$

By substituting Eq. (38) into Eq. (29), the governing equation of $\mathrm{H}_{2}$ molar fraction becomes

$$
\frac{d^{2} y_{\mathrm{H}_{2}}}{d \tilde{x}^{2}}+\frac{\alpha}{D_{\mathrm{H}_{2} \mathrm{O}-\mathrm{H}_{2}}^{e f f}}\left(\frac{1}{D_{\mathrm{H}_{2}, k}^{e f f}}+\frac{1-\alpha y_{\mathrm{H}_{2}}}{D_{\mathrm{H}_{2} \mathrm{O}-\mathrm{H}_{2}}^{e f f}}\right)^{-1}\left(\frac{d y_{\mathrm{H}_{2}}}{d \tilde{x}}\right)^{2}-\frac{A_{v} J_{n, a} R T t_{a n}}{2 \mathrm{FP}}\left(\frac{1}{D_{\mathrm{H}_{2, k}}^{e f f}}+\frac{1-\alpha y_{\mathrm{H}_{2}}}{D_{\mathrm{H}_{2} \mathrm{O}-\mathrm{H}_{2}}^{e f f}}\right)=0
$$

Equation (39) is in the form of an ordinary differential equation, which can be solved by involving the following initial conditions. In Eqs. (40) and (41), the Dalton's law of an ideal gas, $y_{\mathrm{H}_{2}}=P_{\mathrm{H}_{2}} / P_{a \text {,tot }}$, $P_{a, t o t}$ is the total gaseous pressure at the anode side and the initial conditions are following as;

$$
\begin{aligned}
&\left.y_{\mathrm{H}_{2}}\right|_{\widetilde{X}=0}=y_{\mathrm{H}_{2}}^{0} \\
&\left.\frac{d y_{\mathrm{H}_{2}}}{d \tilde{x}}\right|_{\tilde{x}=0}=\frac{-R T J_{\text {total }}}{2 F P t_{\text {an }}}\left(\frac{1}{D_{\mathrm{H}_{2, k}}^{e f f}}+\frac{1-\alpha y_{\mathrm{H}_{2}}}{D_{\mathrm{H}_{2} \mathrm{O}-\mathrm{H}_{2}}^{\text {eff }}}\right)
\end{aligned}
$$

The molar fraction of $\mathrm{H}_{2} \mathrm{O}$ can be obtained by $y_{\mathrm{H}_{2} \mathrm{O}}=1-y_{\mathrm{H}_{2}}$.

In the above mentioned equations, the gas molar fraction, gas diffusion coefficients, current density, and the overpotential are dependent of depth in the vertical direction $(x)$. Due to the complicated phenomena involved, an iterative scheme is used to solve the non-linear equations. The iterative computation is successful if a convergence is obtained. Therefore, the differential equation was solved numerically in MATLAB [36]. After obtaining the distributions of species concentration, current densities, and overpotentials, the overall electrode overpotential can be determined [20].

$$
\tilde{\eta}_{t, a}=\left(\tilde{\phi}_{e, a}^{0}-\tilde{\phi}_{i, a}^{0}\right)-\left(\tilde{\phi}_{e, a}(\tilde{x}=0)-\tilde{\phi}_{i, a(\tilde{x}=1)}\right)
$$


where $\tilde{\eta}_{t, a}=\frac{\eta_{t, a}}{E_{r}}$ and $\tilde{\phi}=\frac{\phi}{E_{r}}$. The superscript 0 represents the equilibrium state or note that $\left(\tilde{\phi}_{e, a}^{0}-\tilde{\phi}_{i, a}^{0}\right)$ is the dimensionless equilibrium potential of the electrode, calculated on the basis of thermodynamic considerations [20].

\subsection{Cathode side modeling}

The configuration of a SOFC cathode can be simply modeled similar to anode that in previously shown by replace the electronic conducting particles with LSM (Strontium - doped Lanthanum Manganite) and the ionic conducting particles with YSZ (Yttria - Stabilized Zirconia). The reaction processes occur simultaneously as the reaction at the anode side. The oxidant (oxygen) is introduced at the cathode side where it diffuses through the porous cathode structure and reacts with electrons from the external circuit to produce $\mathrm{O}^{2-}$ at the vicinity of active sites. Then, they are transferred to anode side through electrolyte. According to Butler -Volmer equation [23], volumetric current density produced due to $\mathrm{O}_{2}$ reduction in cathode, $R_{c}\left(\mathrm{~A} \mathrm{~m}^{-3}\right)$ can be determined from;

$$
R_{c}=A_{v} J_{0, r e f}^{O_{2}}\left\{\left(\frac{c_{O_{2}}}{c_{O_{2}, r e f}}\right)^{\gamma_{O_{2}}}\left(\exp \left(\frac{\alpha z F \eta_{C}}{R T}\right)-\exp \left(-\frac{(1-\alpha) z F \eta_{C}}{R T}\right)\right)\right\}
$$

Equations (43) can be written in the dimensionless form as;

$$
\begin{gathered}
\widetilde{R}_{C}=\left(\frac{c_{O_{2}}}{c_{O_{2}, r e f}}\right)^{\gamma_{O_{2}}}\left\{\exp \left(\alpha E_{1} \tilde{\eta}_{c}\right)-\exp \left(-(1-\alpha) E_{1} \tilde{\eta}_{c}\right)\right\} \\
\text { or } \quad \widetilde{R}_{C}=\left(\frac{x_{O_{2}}}{x_{O_{2}, r e f}}\right)^{\gamma_{O_{2}}}\left(\frac{P}{P_{\text {ref }}}\right)^{\gamma_{O_{2}}}\left(\frac{T_{r e f}}{T}\right)^{\gamma_{O_{2}}}\left\{\exp \left(\alpha E_{1} \tilde{\eta}_{c}\right)-\exp \left(-(1-\alpha) E_{1} \tilde{\eta}_{c}\right)\right\}
\end{gathered}
$$

The dimensionless parameters in Eqs. (44) and (45) are defined below;

$$
\widetilde{R}_{c}=\frac{R_{c}}{A_{v} J_{0, \text { ref }}^{O_{2}}}
$$

where $\tilde{\eta}_{c}=\eta_{c} / E_{r}$ is the dimensionless overpotential at the cathode and $\eta_{c}$ is the overpotential at the cathode $(\mathrm{V}) . E_{l}=\left(E_{r}\right) /(R T / z F), \quad E_{r}$ is the reversible cell potential $(\mathrm{V})$ that is obtained from Nernst 's equation.

Similar to the anode, the coupled electrochemical reactions and transport behaviors at the cathode can be determined in the dimensionless form as shown below; 


$$
\begin{array}{r}
\frac{d^{2} \tilde{\eta}_{c}}{d \tilde{x}^{2}}=\widetilde{R}_{c}\left[\frac{A_{v} J_{0, r e f}^{O_{2}}\left(t_{c a t}\right)^{2}}{E_{r}}\left(\rho_{i, c}^{e f f}+\rho_{e, c}^{e f f}\right)\right] \\
\widetilde{J}_{n, c}=\left\{\frac{P_{O_{2}}}{P^{0}} \exp \left(\alpha E_{1} \tilde{\eta}_{c}\right)-\exp \left(-(1-\alpha) E_{1} \tilde{\eta}_{c}\right)\right\}
\end{array}
$$

where , $\tilde{J}_{n, c}=\left(J_{n, c} / J_{0, c}^{r e f}\right)$. Similar to the anode, the boundary conditions are;

$$
\begin{array}{ll}
\text { at } \quad \tilde{x}=0 ; \widetilde{J}_{e, c}=\widetilde{J}_{\text {total }}=1 \text { and }\left.\frac{d \tilde{\eta}_{c}}{d \tilde{x}}\right|_{\tilde{x}=0}=\left(-\rho_{e, c}^{e f f} J_{\text {total }}\right) \frac{t_{c a t}}{E_{r}} \\
\text { at } \quad \tilde{x}=1 ; \tilde{J}_{i, c}=\widetilde{J}_{\text {total }}=1 \text { and }\left.\frac{d \tilde{\eta}_{c}}{d \tilde{x}}\right|_{\tilde{x}=1}=\left(\rho_{i, c}^{e f f} J_{\text {total }}\right) \frac{t_{c a t}}{E_{r}}
\end{array}
$$

This model was studied on an anode - supported SOFC, so a cathode is really thin when comparing to an anode. Because of the flux of nitrogen does not participate in the electrochemical reaction on the cathode side, only the oxygen becomes part of the electrochemical reaction at the cathode. Due to the cathode is very thin in the anode - supported SOFC, so the concentration of $\mathrm{O}_{2}$ can be determined by self-diffusion mechanism. The self-diffusion mechanism theory to determine the $\mathrm{O}_{2}$ profile is suitable for the thin porous cathode that was recommended in many literatures [24, 37 $38]$ and can be expressed as follow;

$$
\begin{gathered}
J_{O_{2}}=-D_{c} \nabla C_{O_{2}}+y_{O_{2}} \delta_{O_{2}} J_{O_{2}} \\
\delta_{O_{2}}=\frac{D_{O_{2}, k(e f f)}}{D_{O_{2}, k(e f f)}+D_{O_{2}-N_{2}(e f f)}}
\end{gathered}
$$

where $J_{O_{2}}$ is oxygen mol flux $\left(\mathrm{mol} \mathrm{s}^{-1}\right), C_{O_{2}}$ is $\mathrm{O}_{2}$ concentration $\left(\mathrm{mol} \mathrm{m}{ }^{-3}\right)$ and $y_{O_{2}}$ is $\mathrm{O}_{2}$ molar fraction. Therefore, for one - dimensional diffusion

$$
J_{O_{2}}=-D_{O_{2}(e f f)} \frac{d C_{O_{2}}}{d x}+y_{O_{2}} \delta_{O_{2}} J_{O_{2}}
$$

Because $J_{O_{2}}=-J_{e, c} / 4 F$ and $d C_{O_{2}}=d p_{O_{2}} / R T$, so

$$
\frac{d P_{O_{2}}}{P_{c, t o t}-\delta_{O_{2}} P_{O_{2}}}=\frac{R T J_{e, c}}{4 F D_{O_{2}(e f f)} P_{c, t o t}} d x
$$

Integrating this equation with the boundary condition $P_{\mathrm{O}_{2}}=P_{\mathrm{O}_{2}}^{0}$ at the cathode surface yields

$$
\ln \left(\frac{\left(P_{c, t o t} / \delta_{O_{2}}\right)-P_{O_{2}}}{\left(P_{c, t o t} / \delta_{O_{2}}\right)-P_{O_{2}}^{0}}\right)=\frac{\delta_{O_{2}} R T J_{e, c}}{4 F D_{O_{2}(e f f)} P_{c, t o t}} t_{c a t}
$$

Therefore, the partial pressure of oxygen at the cathode reaction sites is 


$$
P_{O_{2}}=\frac{P_{c, t o t}}{\delta_{O_{2}}}-\left(\frac{P_{c, t o t}}{\delta_{O_{2}}}-P_{O_{2}}^{0}\right) \exp \left(\frac{\delta_{O_{2}} R T J_{e, c} t_{c a t}}{4 F D_{c(e f f)} P_{c, t o t}}\right)
$$

where

$$
\frac{1}{D_{O_{2}(e f f)}}=\frac{\tau}{\varepsilon}\left(\frac{1}{D_{O_{2}, k}}+\frac{1}{D_{O_{2}-N_{2}}}\right)
$$

and

$$
D_{c, e f f}=D_{O_{2}(e f f)}
$$

The differential form of Eq. (56) is

$$
\frac{d P_{O_{2}}}{d x}=-\frac{R T J_{e, c}}{4 F D_{O_{2}}^{e f f} P_{c, t o t}}\left(P_{c, t o t}-\left(D_{O_{2}, k}^{e f f} /\left(D_{O_{2}, k}^{e f f}+D_{O_{2}-N_{2}}^{e f f}\right)\right) \cdot P_{O_{2}}\right)
$$

From Eq. (59), the dimensionless form can be determined by;

$$
\frac{d \widetilde{P}_{O_{2}}}{d \tilde{x}}=\left(-\frac{R T J_{e, c}}{4 F D_{O_{2}}^{e f f} P_{c, t o t}}\left(P_{c, t o t}-\left(D_{O_{2}, k}^{e f f} /\left(D_{O_{2}, k}^{e f f}+D_{O_{2}-N_{2}}^{e f f}\right)\right) \cdot P_{O_{2}}\right)\right) \frac{t_{c a t}}{P_{c, t o t}}
$$

where $\widetilde{P}_{O_{2}}=\frac{P_{O_{2}}}{P_{c, t o t}}, P_{c, t o t}$ is the total gaseous pressure at the cathode side and from Dalton's law of an ideal gas is $y_{\mathrm{O}_{2}}=P_{\mathrm{O}_{2}} / P_{c, \text { tot }}$ or Eq. (60) becomes ;

$$
\frac{d y_{O_{2}}}{d \tilde{x}}=\left(-\frac{R T J_{e, c}}{4 F D_{O_{2}}^{e f f} P_{c, t o t}}\left(P_{c, t o t}-\left(D_{O_{2}, k}^{e f f} /\left(D_{O_{2}, k}^{e f f}+D_{O_{2}-N_{2}}^{e f f}\right)\right) \cdot P_{O_{2}}\right)\right) \frac{t_{c a t}}{P_{c, t o t}}
$$

The boundary condition for $\mathrm{O}_{2}$ transport is $\widetilde{P}_{\mathrm{O}_{2}}=\widetilde{P}_{\mathrm{O}_{2}}^{0}$ at $\tilde{x}=0$ or $\left.y_{\mathrm{O}_{2}}\right|_{\widetilde{X}=0}=y_{\mathrm{O}_{2}}^{0}$

The overall dimensionless cathode overpotentials can be determined by Eq. (62) [20],

$$
\tilde{\eta}_{t, c}=\left(\tilde{\phi}_{i, c}^{0}-\tilde{\phi}_{e, c}^{0}\right)-\left(\tilde{\phi}_{i, c(\tilde{x}=1)}-\tilde{\phi}_{e, c(\tilde{x}=0)}\right)
$$

\subsection{The electrolyte modeling}

The dense electrolyte is used to conduct $\mathrm{O}^{2-}$ from the cathode side to electrochemically reaction zone and react with reactant (hydrogen) at the vicinity of the anode active sites to produce $\mathrm{H}_{2} \mathrm{O}$ and electrons. These electrons flow to the cathode side via an external circuit traveling through an electrical load or resistor. It is typically made from Yttria - Stabilized Zirconia (YSZ). The dimensionless overpotential of the dense electrolyte can be determined by Ohm's law,

$$
\tilde{\eta}_{\text {elec }}=\frac{J_{\text {total }} R_{\text {elec }} t_{\text {elec }}}{E_{r}}
$$

where $R_{\text {elec }}$ and $t_{\text {elec }}$ are the resistivity $(\Omega \mathrm{m})$ and thickness $(\mathrm{m})$ of the electrolyte. 


\section{Model validation}

To determine the effectiveness of the proposed model, the available experimental data [40] was computationally reproduced by using the parameters listed in Table 1. The predicted cell performance by the proposed model is compared with the experimental data found in the literature [40] and is shown in Fig. 2. The performance of the cell is predicted when the cell is supplied with $95 \% \mathrm{H}_{2}$ and $5 \% \mathrm{H}_{2} \mathrm{O}$ as fuel, operating at a temperature and pressure of $800{ }^{\circ} \mathrm{C}$ and $1 \mathrm{~atm}$, respectively. Oxygen composition in the ambient air is used as oxidant. The anode, the cathode and the electrolyte were made of Nickel - doped Yttria - Stabilized Zirconia (Ni/YSZ), Strontium - doped Lanthanum Manganite (LSM or $\mathrm{La}_{0.8} \mathrm{Sr}_{0.2} \mathrm{MnO}_{3}$ ) and Yttria - Stabilized Zirconia (YSZ), with the thickness about $1 \mathrm{~mm}$., $50 \mu \mathrm{m}$. and $10 \mu \mathrm{m}$., respectively.

The present model predictions agree well with the experimental results. It is worth mentioning that all the parameters used in the model validation are obtained from Rogers et al. [40].However, some parameters such as particle size, volumetric fraction of electronic and ionic conducting particle given with the other reference recommended by Hussain et al. [23] are used in place of unavailable parameters in Roger et al's work. The value of these parameters (particle sizes, volumetric fraction of electronic and ionic conducting particle etc.) recommended by Hussain et al. are typically used in other researches [23-27, 34, 37]. The value of tortuosity is varied to obtain the best agreement between the present model predictions and the experimental results as shown in Fig. 2. The typical tortuosity value for SOFC electrodes is less than 6 [41]. Hence, the tortuosity value of 2.75 used in the present model predictions is in the typical range and provides the good agreement with the experimental results. The $\mathrm{R}^{2}$-value, an indicator between 0 and 1 which can reveal how closely the predicted values correspond to the experimental data, is obtained for the present model as 0.999 .

\section{Results and discussion}

SOFC modeling needs a lot of number of parameters for calculation. We considered the model at steady state condition with an operating pressure and temperature of $1 \mathrm{~atm}$ and $800{ }^{\circ} \mathrm{C}$. The supplied fuel compositions are $\mathrm{H}_{2}$ and $\mathrm{H}_{2} \mathrm{O}$ and are oxidized is by oxygen in the air. The anode, the cathode and the electrolyte were made of Nickel - doped Yttria - Stabilized Zirconia (Ni/YSZ), Strontium - doped Lanthanum Manganite (LSM or $\mathrm{La}_{0.8} \mathrm{Sr}_{0.2} \mathrm{MnO}_{3}$ ) and Yttria - Stabilized Zirconia 
(YSZ). The dimension of cell components and standard parameters used in calculations are given in Table 2. The electrode porosity and tortuosity are estimated by the equations in an appendix A [28].

This model was employed to gain understanding of the coupled mass transfer and electrochemical phenomena in the electrodes of the SOFC. The present study reveals the working mechanisms of SOFC at the micro - scale level, while demonstrating the use of microstructure effect to enhance the SOFC performance and the micro characteristics of the electrodes are included into the model. The important feature of this work is considered a model in the form of dimensionless governing equations. The predicted cell performances are showed as the dimensionless cell overpotentials at various operating and design conditions. Moreover, parametric analyses were performed to investigate the effects of operating parameters on SOFC performance. The optimal volumetric ratio between the ionic and electronic conducting particles is also proposed in this study. Presently, the most favorable anode - supported configuration with thick anode and thin cathode/electrolyte is considered in this study. The fuel, air composition, and the model parameters from the common data available in the literatures as in Table 2 are used in the calculation and the calculation results are shown in this section.

\subsection{Gas composition distribution in electrodes}

The distribution of gas composition along the electrode depth was studied at the typical operating current density of $10,000 \mathrm{Am}^{-2}$. The electrode porosity $(\varepsilon)$ or the void fraction of the electrode is equal to 0.4 . The volume fraction of electron conducting particles $(\varphi)$ of the solid part of the electrodes is equal to 0.5. The supplied fuel compositions are $\mathrm{H}_{2}$ and $\mathrm{H}_{2} \mathrm{O}$ by molar fraction of 0.95 and 0.05 , respectively. The oxidizer is by oxygen in the standard air. The operating pressure is 1 atm and the operating temperature is $1073 \mathrm{~K}$. The others standard parameters used in the calculation are given in Table 2. Fig. 3 shows the distribution of $\mathrm{H}_{2}$ and $\mathrm{H}_{2} \mathrm{O}$ molar fraction in the anode region Fig.4 shows distribution of $\mathrm{O}_{2}$ molar fraction in the cathode region. In Figs. 3 and 4 , the $\mathrm{x}-$ axis represents the anode distance, whereas y - axis represents $\mathrm{H}_{2}$ and $\mathrm{H}_{2} \mathrm{O}$ molar fraction in Fig. 3 and $\mathrm{O}_{2}$ molar fraction in Fig. 4. In Fig. 3, the molar fraction of $\mathrm{H}_{2}$ decreases considerably from anode surface $\left(\tilde{x}_{a}=0\right)$ towards the electrolyte interface $\left(\tilde{x}_{a}=1\right)$, and the molar fraction of $\mathrm{H}_{2} \mathrm{O}$ decreases from the electrolyte interface $\left(\tilde{x}_{a}=1\right)$ towards the anode surface $\left(\tilde{x}_{a}=0\right)$. In Fig. 4, the molar fraction of $\mathrm{O}_{2}$ insignificantly decreases from cathode surface $\left(\tilde{x}_{c}=0\right)$ towards the electrolyte interface $\left(\tilde{x}_{c}=1\right)$. 
Figure 3 indicates the importance of gas transport in the thick anode. In addition, the thin cathode shows insignificant mass transfer resistance as can be seen in Fig.4.

\subsection{The effect of electrode microstructure on the electrode performance}

Because one of the performance of the SOFC was known to strongly depend on the electrode properties i.e. the volume fraction of the electron conducing particle in an electrode $(\varphi)$, the electrode particle size. All referring parameters are related to the electrode performance for electrochemical reaction. Therefore, in this study the microstructure parameter relation are established and used to determine the electrode performance by investigating the effects of electrode microstructure on the SOFC overpotentials and the current density.

Figure 5 shows the effect of dimensionless particle radius $\left(\tilde{r}_{a}\right)$ on the dimensionless anode overpotentials $\left(\tilde{\eta}_{a}\right)$ and Fig. 6 displays the effect of dimensionless particle radius $\left(\tilde{r}_{c}\right)$ on the dimensionless cathode overpotentials $\left(\tilde{\eta}_{c}\right)$. In Fig. 5 the particle size of the electrode $\left(\tilde{r}_{a}\right)$ is varied under the operating pressure and temperature of $1 \mathrm{~atm}$ and $1073 \mathrm{~K}$. The typical operating current density of $10,000 \mathrm{~A} \mathrm{~m}^{-2}$. The electrode porosity $(\varepsilon)$ or the void fraction of the electrode is set to be equal to 0.4 . The volumetric fraction of electron conducting particles $(\varphi)$ of the solid part of the electrodes is set to 0.5. The supplied fuel are $\mathrm{H}_{2}$ and $\mathrm{H}_{2} \mathrm{O}$ with the molar fraction of 0.95 and 0.05 , respectively and are oxidized is by oxygen in the regular standard air with the composition of 0.21 by molar fraction of oxygen and 0.79 by molar fraction of nitrogen. The other standard parameters used in the calculation are given in Table 2. In Fig.6 is similar to Fig.5 but it is considered on cathode side. In Fig. 5 , the $\mathrm{x}$-axis represents the dimensionless particle radius $\left(\tilde{r}_{a}\right)$ at the anode side whereas the $\mathrm{y}$ - axis represents the dimensionless anode overpotential $\left(\tilde{\eta}_{a}\right)$. In Fig. 6 , the $\mathrm{x}-$ axis represents the dimensionless particle radius $\left(\tilde{r}_{c}\right)$ at the cathode side whereas the $\mathrm{y}-$ axis represents the dimensionless cathode overpotential $\left(\tilde{\eta}_{c}\right)$. In Fig. 5, the minimum dimensionless anode overpotentials $\left(\tilde{\eta}_{a}\right)$ occur at the sizes of the dimensionless particle radius $\tilde{r}_{a}$ at the value of 0.60 . With the thick porous anode of the anode - supported SOFC structure, so the mass transport through anode for participating in the electrochemical reaction at the electrochemically active sites is limited [32, 37]. The difficulty of the mass transport and the magnitude of the active surface area for the electrochemical reaction of the anode $\left(A_{V}\right)$ that both are depended on the anode particles size. The smaller size of the particle is the larger $A_{V}$ which indicated by Eqs. (2) and (7), so reducing particle 
size can increase the anode reactivity and thus reduces the anode activation overpotential. If it considers in the viewpoint of mass transport through the thick porous anode, in fact that when the particle size is too small, the reactant concentration at the reactive site approaches to zero so the reactant concentration is insufficient for reaction and thus the anode concentration overpotential increases instead. It has been reported $[32,37]$ that the performance of an anode-supported SOFC at high operating current density is governed by the concentration overpotential at the anode side. Finally, it can be concluded that the performance of the thick porous anode depends on a competition effect between electrochemical reaction rate and gas diffusion, which effect by an anode particles size.

In Fig.6 the minimum dimensionless cathode overpotentials $\left(\tilde{\eta}_{c}\right)$ occur at the sizes of the dimensionless particle radius $\tilde{r}_{c}$ at the value of 0.62 . In the case of the cathode because of the cathode is very thin, so the limitation of the mass transport is not a problem with the transport of the reactant mass to the electrochemically active sites as referred in the previous which the oxygen selfdiffusion mechanism theory is suitable for the thin cathode [24, 37 - 38]. Although the mass transport for participating in the electrochemical reaction is not a problem for the thin porous cathode but the performance of the cathode still depends on the electrochemical reaction rate. For the model calculation in this study that the cathode is the standard type that the thickness and the material properties, which included with an operating pressure and temperature at the standard operating condition are showed in Table 2. Thus the electrochemical reaction rate only relate with the active surface area of the cathode which is depend on the size and the number of the cathode particles in an unit volume of the cathode, which also indicated by Eqs. (2) and (7). It can be concluded with the thin porous cathode that the effect of the electrochemical reaction rate is the most important for its performance, which effect by the cathode particle size. Because the anode of an anode - supported SOFC is much thicker than the cathode, therefore its overpotential must be higher than that of the cathode. Thus, the anode microscopic geometry must have more effects on cell performance than the cathode geometry. The study of the effect of the microscopic geometry on the anode side will be showed in the next results.

The effect of volumetric fraction of the electron conducting particle $(\varphi)$ in the solid part of the electrodes on the dimensionless anode overpotentials $\left(\tilde{\eta}_{a}\right)$ at various dimensionless particle radius $\left(\tilde{r}_{a}\right)$ at the anode side is shown in Fig 7. The studied conditions are similar to Fig. 5. In Fig. 7, the $\mathrm{x}-$ axis represents the dimensionless particle radius $\left(\tilde{r}_{a}\right)$ at the anode side whereas the $\mathrm{y}-$ axis represents 
the dimensionless anode overpotential $\left(\tilde{\eta}_{a}\right)$. It can be seen that $\tilde{\eta}_{a}$ decreases when $\varphi$ in the reaction zone is increased from 0.4 to 0.5 , and it increases when $\varphi$ is increased from 0.5 to 0.6 . The changes in $\tilde{\eta}_{a}$ with $\varphi$ demonstrate the fact that the largest active area is achieved when the dimensions and volume fractions of the ion conducting and electron conducting particles are equal $[20,23]$. When $\varphi$ equals to 0.5 , the volume fraction of ion conducting particles $(1-\varphi)$ of the solid part of the electrodes becomes equal to the volume fraction of electron conducting particles $(\varphi)$ of the solid part of the electrodes, resulting in the largest active area for electrochemical reaction and hence the best performance. Moreover, the effective ionic and electronic conductivities in the reaction zone layers are functions of $\varphi$. Increasing $\varphi$ beyond 0.5 increases the effective electronic conductivity but decrease the effective ionic conductivity, which results in increasing the ohmic overpotential. In addition the results show at $\varphi$ equal to $0.4,0.5$ and 0.6 that the minimum of $\tilde{\eta}_{a}$ equal to $0.245,0.212$ and 0.226 respectively, occur at $\tilde{r}_{a}$ equal to $0.72,0.60$ and 0.61 , respectively.

Figure 8 shows the effect of dimensionless particle radius $\left(\tilde{r}_{a}\right)$ on dimensionless volumetric current density $\left(\widetilde{R}_{a}\right)$ at the anode side. In Fig. 8 the particle size of the electrode $\left(\tilde{r}_{a}\right)$ is varied under the operating pressure and temperature of $1 \mathrm{~atm}$ and $1073 \mathrm{~K}$. The electrode porosity $(\varepsilon)$ or the void fraction of the electrode is equal to 0.4. The volume fraction of electron conducting particles $(\varphi)$ of the solid part of the electrodes is equal to 0.5 for the highest electrode performance is described by Fig. 7 . The supplied fuel compositions are $\mathrm{H}_{2}$ and $\mathrm{H}_{2} \mathrm{O}$ by molar fraction of 0.95 and 0.05 , respectively. The oxidizer is by oxygen in the standard air. The others standard parameters used in the calculation are given in Table 2. From Fig.8, it can be seen that the maximum $\widetilde{R}_{a}$ occurs at $\tilde{r}_{a}$ equal 0.60 that is at the same particle size of the lowest overpotentials $\left(\tilde{\eta}_{a}\right)$. The higher active surface area of an electrode occurs at the smaller particle size. Therefore, reducing particle size increases the electrode reactivity by reducing the electrode activation overpotential. However, when the particle size is too small, the reactant concentration at the reactive sites approach to zero so the reactant flux is insufficient for reaction. Then, it is necessary to optimize the particle size and the void fraction of the electrode for improving the active surface area and the amount of reactants for electrochemical reaction. From the calculation, at this particle size $\left(\tilde{r}_{a}=0.60\right)$, the active surface area is high and the reactant is sufficient for electrochemical reactions so the highest current density occur at this size. 


\subsection{The effect of operating parameters on the SOFC overpotentials}

Figures 9 and 10 show the effect of operating temperature and the effect of operating pressure on the dimensionless overpotentials $\left(\tilde{\eta}_{a}\right)$ at various dimensionless particle radius $\left(\tilde{r}_{a}\right)$. Both results are considered at the anode side. In Fig. 9, the determined electrode geometry and the supplied fuels are the same as in earlier section. The operating pressure is considered at $1 \mathrm{~atm}$, while the operating temperature is varied. In Fig. 10, all of the calculation parameters are the same as in the case of Fig. 9, except that the operating temperature is set at $1073 \mathrm{~K}$, while the operating pressure is varied. In Figs. 9 and 10 , the $\mathrm{x}$ - axis represents the dimensionless particle radius $\left(\tilde{r}_{a}\right)$, whereas the $\mathrm{y}-$ axis represents the dimensionless anode overpotential $\left(\tilde{\eta}_{a}\right)$.

Figure 9 shows that increasing of temperature can result in increasing of the exchange current density and the ion conductivity of electrolyte, which in turn increase the electrochemical reaction rate. In other words, cell performance increases with the increases of temperature. Fig.9 reveals at the temperature equal to $1073 \mathrm{~K}, 1123 \mathrm{~K}$ and $1173 \mathrm{~K}$, the minimum $\tilde{\eta}_{a}$ equal to $0.212,0.204$ and 0.186 respectively occur at $\tilde{r}_{a}$ equal to $0.6, \quad 0.59$ and 0.58 respectively. Increasing the temperature not only enhances the rate of electrochemical reaction at the reaction sites but also increases the electronic and ionic conductivities of the electron and ion conducting particles. Therefore, the overpotentials of electrodes and ohmic overpotentials of electrolyte decrease with increasing of temperature which in turn minimizes the cell potential loss or cell overpotentials and thereby enhances the cell performance. These phenomena indicate that high temperature is desirable for SOFC from the viewpoint of energy efficiency. However, high temperature limits material selection and also causes problems associated with SOFC long-term stability, such as thermal mismatch and detachment of electrode layers from the electrolyte. Therefore, it is important to develop new materials with high ionic conductivity and high catalytic activity at intermediate and low temperatures. For higher performance, the optimum relations of electrode microstructure parameters can be used to enhance the cell performance. Figure 10 shows the results at the operating pressure equal to $1 \mathrm{~atm}, 3 \mathrm{~atm}$ and $5 \mathrm{~atm}$, the minimum $\tilde{\eta}_{a}$ equal to 0.212 , 0.147 and 0.119 occurs at $\tilde{r}_{a}$ equal to $0.60,0.65$ and 0.72 respectively. At high pressure, the electrode overpotential is lower than that at low pressure. With the increase of pressure, the reactant concentration at the reaction sites increases. This in turn enhances the rate of electrochemical reaction and hence produces better performance. However, increase in pressure creates other difficulties, such as limitation on material selection, gas sealing, and mechanical strength of the cell components [46]. 
The model analysis shows the cell performance strongly depend on the electrode microstructure, i.e. the volumetric composition of the electrodes and the dimensions of the particles. By combining the microstructure effects in the SOFC analysis shows effective possibility of decreasing electrode overpotential and hence improves the cell performance. In addition, the study results substantiate the fact that SOFC overpotential could be effectively decreased by increasing the operating temperature, as well as the operating pressure. Therefore, the concept of microscopic model SOFC is feasible and has great potential to improve the SOFC performance by simply modifying the electrode microstructures.

\section{Conclusions}

A micro - scale model of a Solid Oxide Fuel Cell (SOFC) involving the mass transfer in the electrode together with electrochemical reaction, the transport of electrons and ions in the respective electron - conducting and ion - conducting particles in the electrodes packed with spherical - shaped particles was mathematically developed. An important feature of this work is the modeling is modeled with the couples of useful dimensionless parameters in order to represent the characteristics of the cell. A theoretical model has been presented for the evaluation of the performance of an electrode formed by a mixture of electronic conducting and ionic conducting particles. The effects of micro scale electrode geometry on the cell performance were also taken into account. Parametric study according to the volumetric fraction of ionic and electronic conducting particles was conducted in order to examine the effects of operating conditions on the cell overpotentials. The model analysis shows the cell performance strongly depend on the electrode microstructure, -i.e. the volumetric composition of the electrode, the size of the particle etc. In addition, the study results substantiate the fact that SOFC overpotential could be effectively decreased by increasing the operating temperature, as well as the operating pressure. The present study reveals the working mechanisms of SOFC caused by the microscopic geometry and demonstrates the promising use of microstructure relations to enhance the SOFC performance. Aside from their electric performance, other properties associated with micro-structural should be further investigated. The model - predicted results are validated with the experimental data found in the literature. A good agreement is obtained between the predicted values and the measured data. 


\section{Acknowledgement}

Authors would like to acknowledge with gratitude the financial support from the Thailand National Research University Fund, the Thailand Higher Education Commission Fund and the Thailand Research Fund.

\section{Appendices}

\subsection{Appendix A : Tortuosity model}

The geometrical model for tortuosity of streamline in three dimensional porous media when the particles have the shape as spherical which used in this SOFC modeling obtained by Meijuan Yun et al [28]. The using equations are shown below.

$$
\begin{aligned}
& \tau=\left(\tau_{1}+\tau_{2}\right) / 2 \\
& \tau_{1}=\left[\begin{array}{c}
6 \sqrt{3 p^{2}+12 p+8}-\left(3 p^{2}+12 p+4\right) \arcsin \frac{2}{\sqrt{3}(p+2)} \\
-6(p+2)^{2} \arctan \frac{-2}{\sqrt{3 p^{2}+12 p+8}}
\end{array}\right] /[8 \sqrt{3}(p+2)] \\
& \tau_{2}=1+(\pi-2) /\left(\frac{4 \pi}{3(1-\varepsilon)}+\left(\frac{4 \pi}{3(1-\varepsilon)}\right)^{1 / 3}-2 \times\left(\frac{4 \pi}{3(1-\varepsilon)}\right)^{2 / 3}\right) \\
& p=\frac{2}{3} \sqrt{\frac{\sqrt{3} \pi}{1-\varepsilon}}-2 \\
& \varepsilon=1-4 \pi /\left(3 \sqrt{3}(2+d / r)^{2}\right)
\end{aligned}
$$

where the parameter $\varepsilon$ is the porosity for the spherical particle packed electrode.

\subsection{Appendix B : Binary diffusion coefficient}

The Chapman-Enskog theory is applied to determine the binary diffusion coefficient $\left(D_{i, j}\right)$ as written by Bird et al [35].

$$
D_{i, j}=0.0018583\left(\frac{T^{3 / 2}}{p \sigma_{i j}^{2} \Omega_{D_{i j}}}\right)\left(\frac{1}{M_{i}}+\frac{1}{M_{j}}\right)^{1 / 2}
$$


where $\sigma_{i j}=\left(\sigma_{i}+\sigma_{j}\right) / 2$ is the collision diameter (in $A$ ), $p$ is total pressure (in atm), $M_{i}$ and $M_{j}$ are molecular weight of species $i$ and $j, \Omega_{D_{i j}}$ is the collision integral based on the Lennard - Jones potential [35];

$$
\Omega_{D i j}=\frac{1.06036}{\left(k T / \varepsilon_{i j}\right)^{0.15610}}+\frac{0.19300}{\exp \left(0.47635 \times\left(k T / \varepsilon_{i j}\right)\right)}+\frac{1.03587}{\exp \left(1.52996 \times\left(k T / \varepsilon_{i j}\right)\right)}+\frac{1.76474}{\exp \left(3.89411 \times\left(k T / \varepsilon_{i j}\right)\right)}
$$

where $k$ is the Boltzmann constant which is equal to $1.38066 \times 10^{23} \mathrm{~J} \mathrm{~K}^{-1}$ and $\varepsilon_{i j}$ is the characteristic Lennard - Jones energy given by $\varepsilon_{i j}=\left(\varepsilon_{i} \varepsilon_{j}\right)^{1 / 2}$. The parameters used for calculation of $D_{i j}$ are listed in the Table 3.

\section{References}

[1] S.C. Singhal, K. Kendall, High Temperature Solid Oxide Fuel Cells: Fundamentals Design and Applications (Elsevier, Oxford, 2003)

[2] J. Larminie, A. Dicks, Fuel Cell Systems Explained (John Wiley \& Sons, Chichester, 2003)

[3] P.A. Ramakrishna, S. Yang, C.H. Sohn, J. Power Sources 158, 378 (2006)

[4] Y.H. Koh, J.J. Sun, W.Y. Choi, H.E. Kim, J. Power Sources 161, 1023 (2006)

[5] Y. Yang, G. Wang, H. Zhang, W. Xia, J. Power Sources 173, 233 (2007)

[6] J.J. Hwang, C.K. Chen, D.Y. Lai, J. Power Sources 140, 235 (2005)

[7] J.J. Hwang, C.K. Chen, D.Y. Lai, J. Power Sources 143, 75 (2005)

[8] J.P.P. Huijsmans, F.P.F. Van Berkel, G.M. Christie, J. Power Sources 71, 107 (1998)

[9] K. Choy, W. Bai, S. Charojrochkul, B.C.H. Steele, J. Power Sources 71, 361 (1998)

[10] J.M. Ralph, A.C. Schoeler, M. Krumpelt, J. Mater. Sci. 36, 1161 (2001)

[11] B.C.H. Steele, Solid State Ionics 134, 3 (2000)

[12] H. Rabat, P. Brault, Fuel Cells 8, 81 (2008)

[13] D. Beckel, A. Bieberle - Hutter, A. Harvey, A. Infortuna, U.P. Muecke, M. Prestat, J.L.M. Rupp, L.J. Gauckler, J. Power Sources 173, 325 (2007)

[14] E. Rezugina, A.L. Thomann, H. Hidalgo, P. Brault, V. Dolique, Y. Tessier, Surf. Coat. Tech. 204, 2376 (2010)

[15] A. Billard, D. Mercs, F. Perry, C. Frantz, Surf. Coat. Tech. 140, 225 (2001)

[16] C. W. Tanner, K. Z. Fung, A. V. Virkar, J. Electrochem. Soc. 144, 21 (1997) 
[17] S. Sunde, J. Electrochem. Soc. 142, L50 (1995)

[18] S. Sunde, J. Electrochem. Soc. 143, 1123 (1996)

[19] S. Sunde, J. Electrochem. Soc. 143, 1930 (1996)

[20] P. Costamagna, P. Costa, V. Antonucci, Electrochim. Acta 43, 375 (1998)

[21] X.J. Chen, S.H. Chan, K.A. Khor, Electrochim. Acta 49, 1851 (2004)

[22] J. Deseure, Y. Bultel, L. Dessemond, E. Siebert, Electrochim. Acta 50, 2037 (2005)

[23] M.M. Hussain, X. Li, I. Dincer, J. Power Sources 161, 1012 (2006)

[24] M. Ni, M.K.H. Leung, D.Y.C. Leung, J. Power Sources 168, 369 (2007)

[25] M.M. Hussain, X. Li, I. Dincer, Int. J. Hydrogen Energy 34, 3134 (2009)

[26] S.H. Chan, Z.T. Xia, J. Electrochem. Soc. 148, A388 (2001)

[27] S.H. Chan, X.J. Chen, K.A. Khor, J. Electrochem. Soc. 151, A164 (2004)

[28] M. Yun, B. Yu, P. Xu and J. Wu., Can. J. Chem. Eng. 84, 301 (2006)

[29] R. Krishna, J.A. Wesselingh, Chem. Eng. Sci. 52, 861 (1997)

[30] R. Suwanwarangkul, E. Croiset, M.W. Fowler, P.L. Douglas, E. Entchev, M.A. Douglas, J. Power Sources 122, 9 (2003)

[31] J.W. Veldsink, R.M.J. van Damme, G.F. Versteeg, W.P.M. van Swaaij, Chem. Eng. J. 57, $115(1995)$

[32] H. Yakabe, M. Hishinuma, M. Uratani , Y. Matsuzaki, I. Yasuda, J. Power Sources 86, 423 (2000)

[33] W. Lehnert, J. Meusinger, F. Thom, J. Power Sources 87, 57 (2000)

[34] S.H. Chan, Z T. Xia, J. Appl. Electrochem. 32, 339 (2002)

[35] R.B. Bird, W.E. Stewart, E.N. Lightfoot, Transport Phenomena, 2nd edn. (John Wiley \& Sons, New York, 2001)

[36] A. Gilat, V. Subramaniam, Numerical Methods for Engineers and Scientists: an Introduction with Applications using MATLAB, 1st edn. (John Wiley \& Sons Inc, USA, 2008)

[37] S.H. Chan, K.A. Khor, Z.T. Xia, J. Power Sources 93, 130 (2001)

[38] C. Berger, Handbook of Fuel Cell Technology, (Prentice Hall, Englewood Cliffs, NJ, 1968)

[39] B. Tod, J.B. Young, J. Power Sources 110, 186 (2002) 
[40] W.A. Rogers, R.S. Gemmen, C. Johnson, M. Prinkey, M. Shahnam, Fuel Cell Sci. Eng. Technol. ASME. FUELCELL2003 - 1762, 517 (2003)

[41] M. Iwata, T. Hikosaka, M. Morita, T. Iwanari, K. Ito, K. Onda, Y. Esaki, Y. Sakaki, S. Nagata, Solid State Ionics 132, 297 (2000)

[42] J. Comiti, M. Renaud, Chem. Eng. Sci. 44, 1539 (1989)

[43] W. Kim, A.V. Virkar, K.Z. Fung, K. Mehta, S.C. Singhal, J. Electrochem. Soc. 146, 69 (1999)

[44] H.Y. Zhu, R.J. Kee, J. Power Sources 117, 61 (2003)

[45] R. O’Hayre, S.W. Cha, W. Colella, F.B. Prinz, Fuel Cell Fundamentals (John Wiley \& Sons, New York, 2006)

[46] N.Q. Minh, T. Takahashi, Science and Technology of Ceramic Fuel Cells (Elsevier Science, Amsterdam, 1995)

\section{Nomenclature}

$A_{v} \quad$ Active surface area per unit volume $\left[\mathrm{m}^{2} \mathrm{~m}^{-3}\right]$

$\widetilde{A}_{v} \quad$ Dimensionless active surface area per unit volume

$D_{i j} \quad$ Binary diffusion coefficient $\left[\mathrm{m}^{2} \mathrm{~s}^{-1}\right]$

$D_{i, k} \quad$ Knudsen diffusion coefficient of the species i $\left[\mathrm{m}^{2} \mathrm{~s}^{-1}\right]$

$D_{i j}^{e f f} \quad$ Effective binary diffusion coefficient $\left[\mathrm{m}^{2} \mathrm{~s}^{-1}\right]$

$E_{r} \quad$ Reversible cell potential [V]

$E^{\circ} \quad$ Standard Nernst potential at $1 \mathrm{~atm}$ and $25^{\circ} \mathrm{C}[\mathrm{V}]$

$F \quad$ Faraday's constant, $96485\left[\mathrm{C} \mathrm{mol}^{-1}\right]$

$J_{e} \quad$ Electronic current density $\left[\mathrm{A} \mathrm{m}^{-2}\right]$

$J_{i} \quad$ Ionic current density $\left[\mathrm{A} \mathrm{m}^{-2}\right]$

$J_{n} \quad$ Transfer current per unit area of reactive surface $\left[\mathrm{A} \mathrm{m}^{-2}\right]$

$J_{\text {total }} \quad$ Total current density $\left[\mathrm{A} \mathrm{m}^{-2}\right]$

$\widetilde{J}_{e} \quad$ Dimensionless electronic current density

$\widetilde{J}_{i} \quad$ Dimensionless ionic current density

$J_{r e f}^{H_{2}}$ Reference exchange current density for $\mathrm{H}_{2}$ oxidation [ $\mathrm{A} \mathrm{m}^{-2}$ ] 
$J_{\text {ref }}^{\mathrm{O}_{2}}$ Reference exchange current density for $\mathrm{O}_{2}$ reduction $\left[\mathrm{A} \mathrm{m}^{-2}\right.$ ]

$M \quad$ Molecular weight $\left[\mathrm{kg} \mathrm{kmol}^{-1}\right]$

$n_{e l} \quad$ Number fraction of electron - conducting particle in the electrode

$n_{i o} \quad$ Number fraction of ion - conducting particle in the electrode

$n_{t} \quad$ Total number of particles in the electrode per unit volume $\left[\mathrm{m}^{-3}\right]$

$N_{i} \quad$ Molar flux of species i $\left[\mathrm{mol} \mathrm{m}^{-2} \mathrm{~s}^{-1}\right]$

$\widetilde{N}_{i} \quad$ Dimensionless molar flux of species i

$p_{e l} \quad$ Probability of percolation of electron - conducting particles in the electrode

$p_{i o} \quad$ Probability of percolation of ion - conducting particles in the electrode

$P \quad$ Pressure [atm]

$P_{H_{2}}^{a} \quad$ Hydrogen partial pressure in anode

$P_{\mathrm{H}_{2} \mathrm{O}}^{a} \quad$ Water partial pressure in anode

$P_{O_{2}}^{c} \quad$ Oxygen partial pressure in cathode

$r_{e l} \quad$ Radius of electron - conducting particles in the electrode [m]

$r_{i o} \quad$ Radius of ion - conducting particles in the electrode [m]

$R \quad$ Universal gas constant, $8.314\left[\mathrm{~J} \mathrm{~mol}^{-1} \mathrm{~K}^{-1}\right]$

$R_{a} \quad$ Volumetric current density produced due to hydrogen oxidation [ $\mathrm{A} \mathrm{m}^{-3}$ ]

$R_{i} \quad$ Reaction rate $\left[\mathrm{mol} \mathrm{m} \mathrm{m}^{-3} \mathrm{~s}^{-1}\right]$

$\vec{r} \quad$ Mean value of the pore radii [m]

$\tilde{r} \quad$ Dimensionless particle radius

$\widetilde{R}_{a} \quad$ Dimensionless volumetric current density produced in the anode

$t_{a n} \quad$ Anode thickness [m]

$t_{\text {cat }} \quad$ Cathode thickness $[\mathrm{m}]$

$t_{\text {elec }} \quad$ Electrolyte thickness [m]

$T \quad$ Temperature [K]

$V_{0} \quad$ Spherical particle volume $\left[\mathrm{m}^{3}\right]$

$x_{a} \quad$ Anode position $[\mathrm{m}]$

$x_{c} \quad$ Cathode position [m]

$\tilde{\mathrm{X}}_{\mathrm{a}} \quad$ Anode dimensionless position

$\tilde{x}_{c} \quad$ Cathode dimensionless position 
$y_{i} \quad$ Molar fraction of species i $\left[\mathrm{mol} \mathrm{mol}^{-1}\right]$

$Z \quad$ Total average particle coordination number in electrode which equal to 6

$Z_{e l} \quad$ Coordination number of electron - conducting particles in the electrode

$Z_{i o} \quad$ Coordination number of ion - conducting particles in the electrode

Greek letters

$\Delta G^{\circ} \quad$ Net standard Gibbs free energy of electrochemical reaction at 1 atm and $25^{\circ} \mathrm{C}$

$\alpha \quad$ Charge transfer coefficient

$\gamma_{H_{2}} \quad$ Reaction order for hydrogen oxidation reaction

$\gamma_{\mathrm{O}_{2}} \quad$ Reaction order for oxygen reduction reaction

$\varepsilon \quad$ Porosity

$\eta_{a} \quad$ Anode activation overpotential [V]

$\eta_{c} \quad$ Cathode activation overpotential [V]

$\tilde{\eta}_{a} \quad$ Dimensionless anode overpotential

$\tilde{\eta}_{c} \quad$ Dimensionless cathode overpotential

$\theta \quad$ Contact angle between electron and ion - conducting particles in the electrode $\left(^{\circ}\right)$

$\sigma \quad$ Electronic conductivity $\left[\mathrm{S} \mathrm{m}^{-1}\right]$

$\tau \quad$ Tortuosity

$\phi_{e} \quad$ Electronic potential [V]

$\tilde{\phi}_{e} \quad$ Dimensionless electronic potential

$\phi_{i} \quad$ Ionic potential [V]

$\tilde{\phi}_{i} \quad$ Dimensionless ionic potential

$\varphi \quad$ Volume fraction of electron conducting particles in the electrode 


\section{Table Captions}

Table 1 Parameters used for model validation (source: Rogers et al. [40])

Table 2 Standard parameters used in the SOFC model calculation

Table 3 List of Lennard - Jones potentials used in calculation (taken from Tod et al. [39])

\section{Figure Captions}

Figure 1. (a) A structure of a unit cell with multiple channels. (b) The cross - sectional representation of a composite anode computational domain.

Figure 2. The comparison between model predictions and experimental results of Rogers et al [40]

Figure 3. $\mathrm{H}_{2}$ and $\mathrm{H}_{2} \mathrm{O}$ molar fraction distribution along anode depth

Figure 4. $\mathrm{O}_{2}$ molar fraction distribution along cathode depth

Figure 5. Effect of dimensionless particle radius $\left(\tilde{r}_{a}\right)$ on dimensionless anode overpotential $\left(\tilde{\eta}_{a}\right)$

Figure 6. Effect of dimensionless particle radius $\left(\tilde{r}_{c}\right)$ on dimensionless cathode overpotential $\left(\tilde{\eta}_{c}\right)$

Figure 7. The effect of volumetric fraction of the electron conducting particle $(\varphi)$ on dimensionless anode overpotentials $\left(\tilde{\eta}_{\mathrm{a}}\right)$ at various dimensionless particle radius of the anode $\left(\tilde{\mathrm{r}}_{\mathrm{a}}\right)$

Figure 8. Effect of dimensionless particle radius $\left(\tilde{r}_{a}\right)$ on dimensionless volumetric current density $\left(\widetilde{R}_{\mathrm{a}}\right)$

Figure 9. Effect of the dimensionless particle radius $\left(\tilde{r}_{a}\right)$ on the dimensionless overpotentials $\left(\tilde{\eta}_{a}\right)$ at various cell operating temperature

Figure 10. Effect of the dimensionless particle radius $\left(\tilde{r}_{a}\right)$ on the dimensionless anode overpotential $\left(\tilde{\eta}_{\mathrm{a}}\right)$ at various cell operating pressure 


\section{Tables}

Table 1

\begin{tabular}{|c|c|}
\hline Parameters & Values \\
\hline Operating temperature, $\mathrm{T}\left({ }^{\circ} \mathrm{C}\right)$ & 800 \\
\hline Total pressure, $\mathrm{P}(\mathrm{atm})$ & 1 \\
\hline Fuel composition, $\mathrm{x}_{\mathrm{H} 2}, \mathrm{x}_{\mathrm{H} 2 \mathrm{O}}$ & $0.95,0.05$ \\
\hline Air composition, $\mathrm{x}_{\mathrm{O} 2}, \mathrm{x}_{\mathrm{N} 2}$ & $0.21,0.79$ \\
\hline Conductivity of electronic conductor of anode, $\sigma_{\mathrm{e}, \mathrm{a}}\left(\mathrm{S} \mathrm{m}^{-1}\right)$ & 71428.57 \\
\hline Conductivity of electronic conductor of cathode, $\sigma_{e, c}\left(\mathrm{~S} \mathrm{~m}^{-1}\right)$ & 5376.34 \\
\hline Conductivity of ionic conductor of anode, $\sigma_{\mathrm{i}, \mathrm{a}}\left(\mathrm{S} \mathrm{m}^{-1}\right)$ & 0.64 \\
\hline Conductivity of ionic conductor of cathode, $\sigma_{i, c}\left(\mathrm{~S} \mathrm{~m}^{-1}\right)$ & 0.64 \\
\hline Electrolyte conductivity, $\kappa_{\text {elec }}\left(\mathrm{S} \mathrm{m}^{-1}\right)$ & 0.64 \\
\hline Anode electrode layer thickness, $\mathrm{t}_{\mathrm{a}}(\mu \mathrm{m})$. & 1000.0 \\
\hline Cathode electrode layer thickness, $t_{c}(\mu \mathrm{m})$. & 50.0 \\
\hline Electrolyte thickness, $\mathrm{t}_{\mathrm{e}}(\mu \mathrm{m})$. & 10.0 \\
\hline Porosity of anode and cathode, $\varepsilon$ & 0.375 \\
\hline Tortuosity of anode and cathode, $\tau$ & 2.75 \\
\hline Pore radius of anode and cathode, $r_{p}(\mu \mathrm{m})$. & 0.75 \\
\hline Contact angle between $\mathrm{e}^{-}$and $\mathrm{O}^{2-}$ conducting particles, $\theta\left({ }^{\circ}\right)[23]$ & 15 \\
\hline Radius of electronic conducting particle, $\mathrm{r}_{\mathrm{el}}(\mu \mathrm{m}).[34]$ & 0.5 \\
\hline Radius of ionic conducting particle, $r_{\text {io }}(\mu \mathrm{m}).[34]$ & 0.5 \\
\hline Reference radius of electrode particle, $\mathrm{r}_{0}(\mu \mathrm{m}).[34]$ & 0.5 \\
\hline Volume fraction of electronic conducting particle, $\varphi[23]$ & 0.5 \\
\hline Volume fraction of ionic conducting particle, $1-\varphi[23]$ & 0.5 \\
\hline Reference $\mathrm{H}_{2}$ concentration, $\mathrm{c}_{\mathrm{H} 2 \text {,ref }}\left(\mathrm{mol} \mathrm{m}^{-3}\right)$ [23] & 10.78 \\
\hline Reference $\mathrm{O}_{2}$ concentration, $\mathrm{c}_{\mathrm{O} 2 \text {,ref }}\left(\mathrm{mol} \mathrm{m}^{-3}\right)$ [23] & 2.38 \\
\hline Reference exchange current density for $\mathrm{H}_{2}$ oxidation, $\mathrm{J}_{0, \text { ref }}^{\mathrm{H}_{2}}\left(\mathrm{~A} \mathrm{~m}^{-2}\right)[23]$ & 1320 \\
\hline Reference exchange current density for $\mathrm{O}_{2}$ reduction, $\mathrm{J}_{0 \text {,ref }}^{\mathrm{O}_{2}}\left(\mathrm{~A} \mathrm{~m}^{-2}\right)$ [23] & 400 \\
\hline Reaction order for $\mathrm{H}_{2}$ oxidation, $\gamma_{\mathrm{H} 2}$ [23] & 0.5 \\
\hline Reaction order for $\mathrm{O}_{2}$ reduction, $\gamma_{\mathrm{O} 2}[23]$ & 0.5 \\
\hline
\end{tabular}


Table 2

\begin{tabular}{|c|c|}
\hline Parameters & Values \\
\hline Operating temperature, $\mathrm{T}\left({ }^{\circ} \mathrm{C}\right)$ & 800 \\
\hline Operating pressure, $\mathrm{P}(\mathrm{atm})$ & 1 \\
\hline $\mathrm{H}_{2}$ and $\mathrm{H}_{2} \mathrm{O}$ in fuel mixture inlet molar fraction & $0.95,0.05$ \\
\hline $\mathrm{O}_{2}$ and $\mathrm{N}_{2}$ in air inlet molar fraction & $0.21,0.79$ \\
\hline Anode thickness, $\mathrm{t}_{\mathrm{a}}(\mu \mathrm{m})$. & 2000 \\
\hline Anode tortuosity, $\tau_{\mathrm{a}}$ & 1.38 \\
\hline Porosity of anode, $\varepsilon_{\mathrm{a}}$ & $\begin{array}{l}\text { (Eq. in an appendix A) } \\
0.4 \\
\text { (Eq. in an appendix A) }\end{array}$ \\
\hline Anode pore radius $\left(r_{p}\right)(\mu \mathrm{m})$. & 0.5 \\
\hline Cathode thickness, $\mathrm{t}_{\mathrm{c}}(\mu \mathrm{m})$. & 60 \\
\hline Cathode tortuosity, $\tau_{\mathrm{c}}$ & $\begin{array}{l}1.38 \\
(\text { Fo in an annendix A) }\end{array}$ \\
\hline Porosity of cathode, $\varepsilon_{\mathrm{c}}$ & $\begin{array}{l}0.4 \\
\text { (Eq. in an appendix A) }\end{array}$ \\
\hline Cathode pore radius ,radius, $r_{p}(\mu \mathrm{m})$. & 0.5 \\
\hline Electrolyte thickness , $\mathrm{t}_{\text {elec }}(\mu \mathrm{m})$. & 60 \\
\hline $\begin{array}{l}\text { Contact angle between } \mathrm{e}^{-} \text {and } \mathrm{O}^{2-} \text { conducting particles, } \theta\left({ }^{\mathrm{o}}\right) \\
{[23]}\end{array}$ & 15 \\
\hline Radius of electronic conducting particle, $\mathrm{r}_{\mathrm{el}}(\mu \mathrm{m}).[34]$ & 0.5 \\
\hline Radius of ionic conducting particle, $r_{\text {io }}(\mu \mathrm{m}).[34]$ & 0.5 \\
\hline Reference radius of electrode particle, $\mathrm{r}_{0}(\mu \mathrm{m}).[34]$ & 0.5 \\
\hline $\begin{array}{l}\text { Reference exchange current density for } \mathrm{H}_{2} \text { oxidation, } \mathrm{J}_{0, \text { ref }}^{\mathrm{H}_{2}} \\
\left(\mathrm{~A} \mathrm{~m}^{-2}\right)[23]\end{array}$ & 1320 \\
\hline $\begin{array}{l}\text { Reference exchange current density for } \mathrm{O}_{2} \text { reduction, } \mathrm{J}_{0 \text {,ref }}^{\mathrm{O}_{2}} \\
\left(\mathrm{~A} \mathrm{~m}^{-2}\right)[23]\end{array}$ & 400 \\
\hline $\begin{array}{l}\text { Total average particle coordination number in electrode, } Z \\
{[20,23]}\end{array}$ & 6 \\
\hline Charge transfer coefficient, $\alpha[26]$ & 0.5 \\
\hline $\begin{array}{l}\text { Conductivity of electronic conductor of anode, } \sigma_{e, a}\left(\mathrm{~S} \mathrm{~m}^{-1}\right) \\
{[23]}\end{array}$ & $2 \mathrm{e} 6$ \\
\hline $\begin{array}{l}\text { Conductivity of electronic conductor of cathode, } \sigma_{e, c}\left(\mathrm{~S} \mathrm{~m}^{-1}\right) \\
{[23]}\end{array}$ & $1 \mathrm{e} 4$ \\
\hline Conductivity of ionic conductor of anode, $\sigma_{i, a}\left(\mathrm{~S} \mathrm{~m}^{-1}\right)$ [23] & $\begin{array}{l}3.44 \mathrm{e} 4 *(\exp (- \\
10300 / \mathrm{T}))\end{array}$ \\
\hline Conductivity of ionic conductor of cathode, $\sigma_{i, c} \quad\left(\mathrm{~S} \mathrm{~m}^{-1}\right)[23]$ & $\begin{array}{l}3.44 \mathrm{e} 4 *(\exp (- \\
10300 / \mathrm{T}))\end{array}$ \\
\hline Faraday constant, $\mathrm{F} \quad\left(\mathrm{C} \mathrm{mol}^{-1}\right)[23]$ & 96485 \\
\hline
\end{tabular}


Table 3

\begin{tabular}{|cccccccc|}
\hline Gas species & $\mathrm{CH}_{4}$ & $\mathrm{H}_{2} \mathrm{O}$ & $\mathrm{CO}_{2}$ & $\mathrm{CO}$ & $\mathrm{H}_{2}$ & $\mathrm{~N}_{2}$ & $\mathrm{O}_{2}$ \\
\hline$\sigma_{\mathrm{i}}^{\mathrm{a}}$ & 3.758 & 2.641 & 3.941 & 3.69 & 2.827 & 3.798 & 3.467 \\
\hline$\varepsilon_{\mathrm{i}}^{\mathrm{a}}$ & 148.6 & 809.1 & 195.2 & 91.7 & 59.7 & 71.4 & 106.7 \\
\hline
\end{tabular}

\section{Figures}

Figure 1 (a)

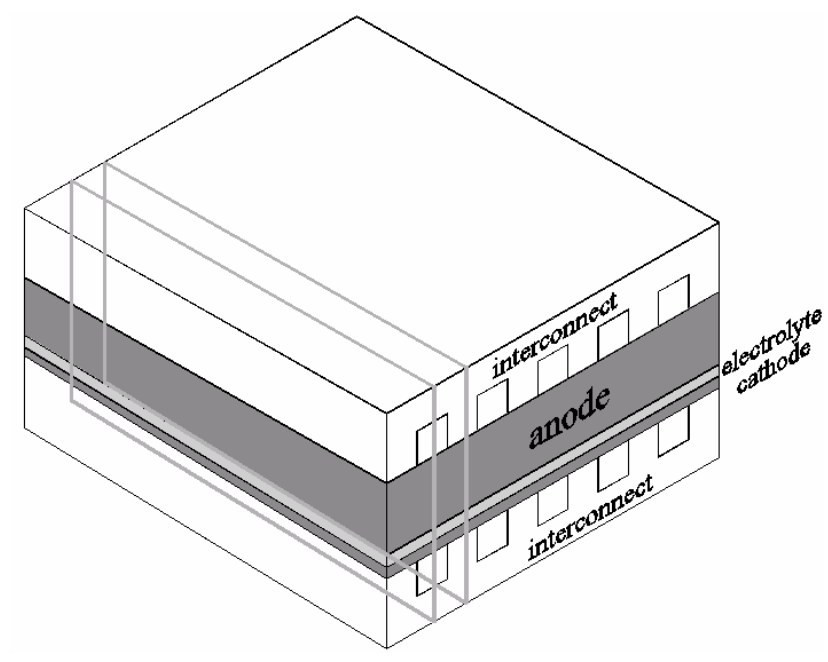

Figure 1 (b)

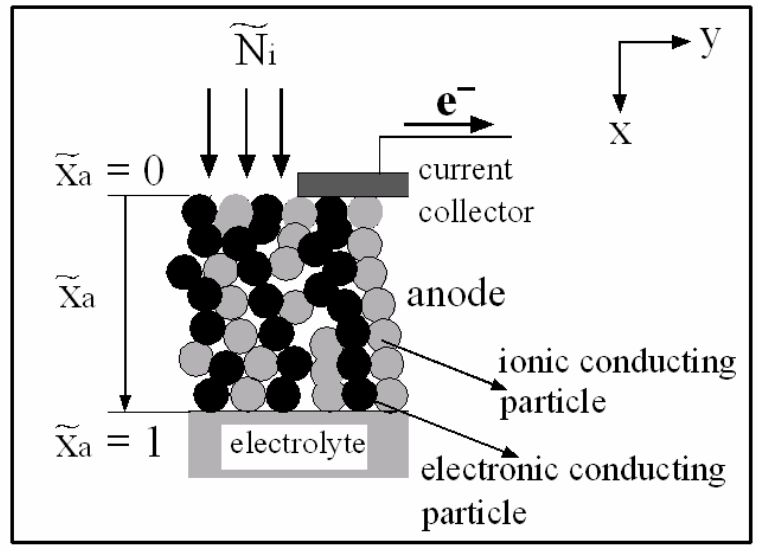

computational domain 
Figure 2.

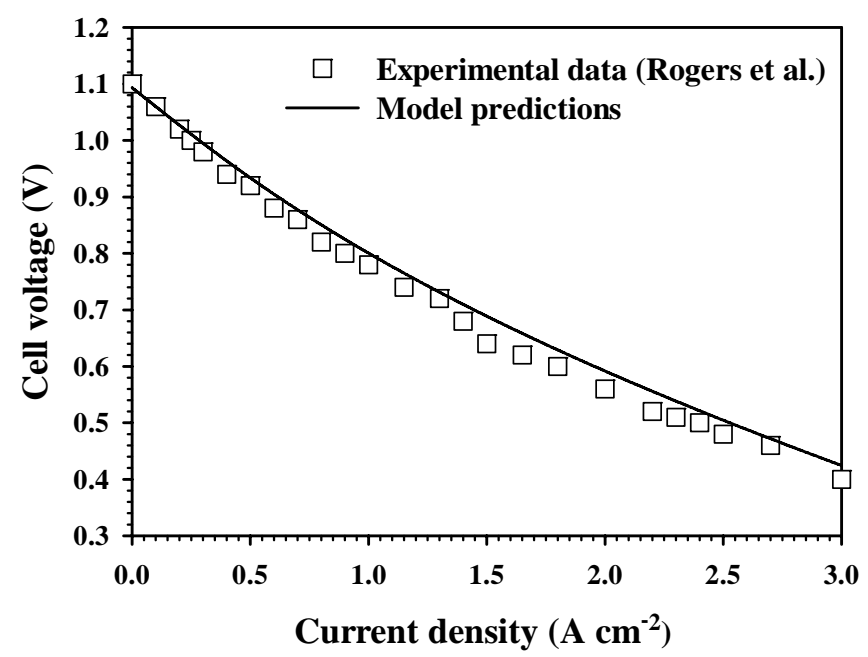

Figure 3.

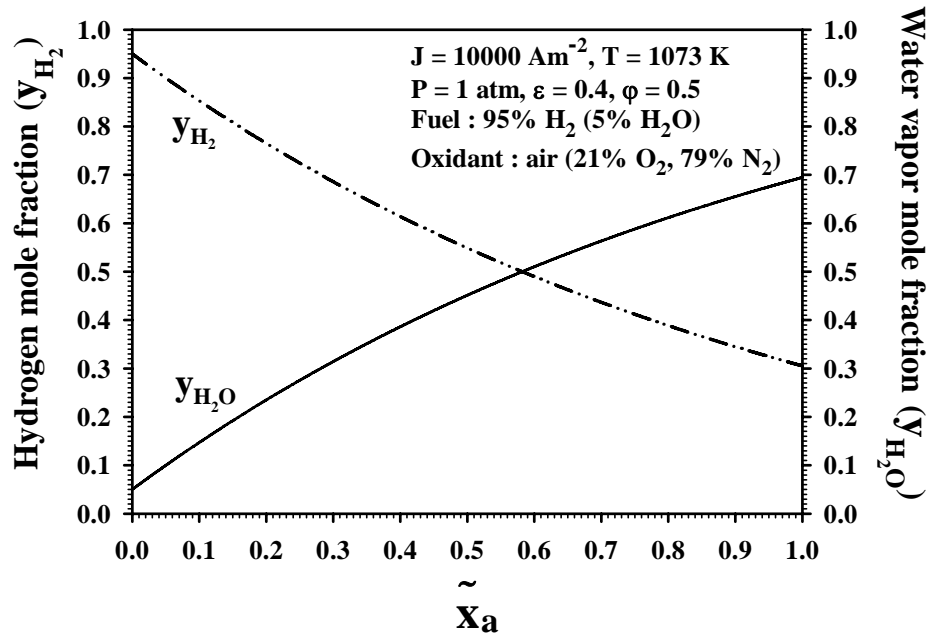

Figure 4.

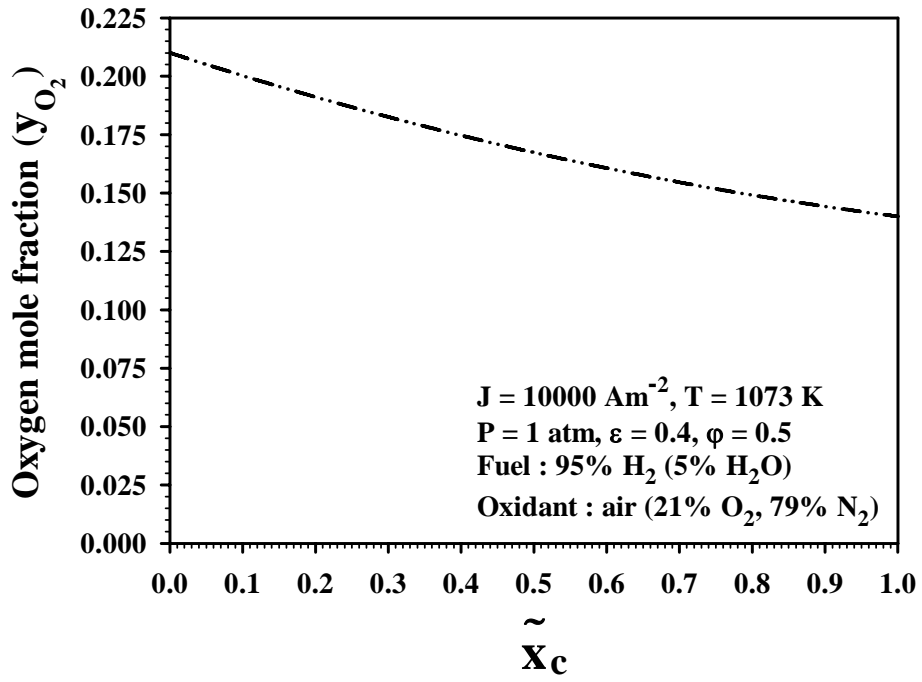


Figure 5.

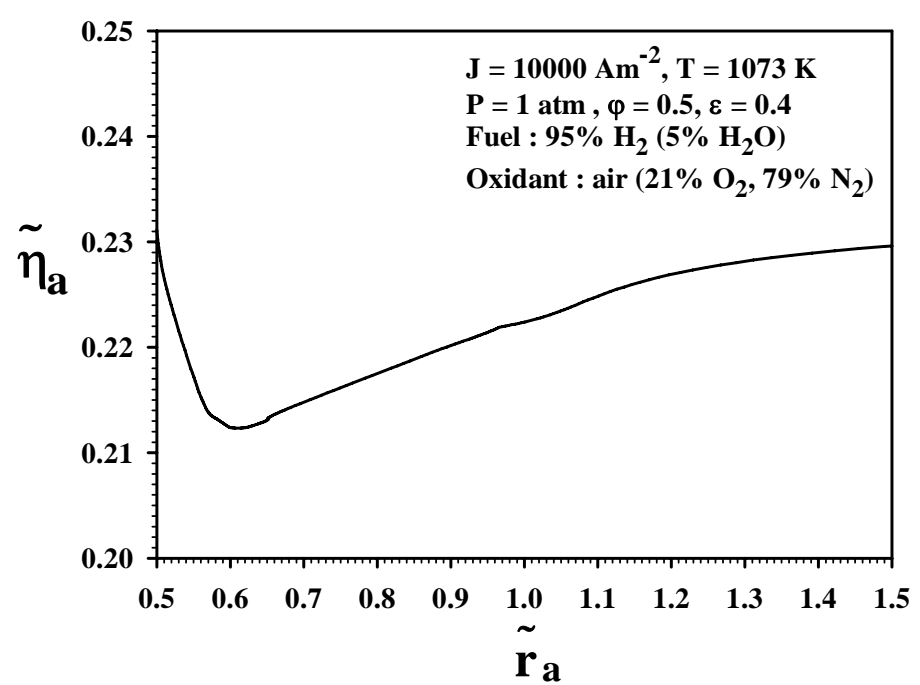

Figure 6.

Figure 7.
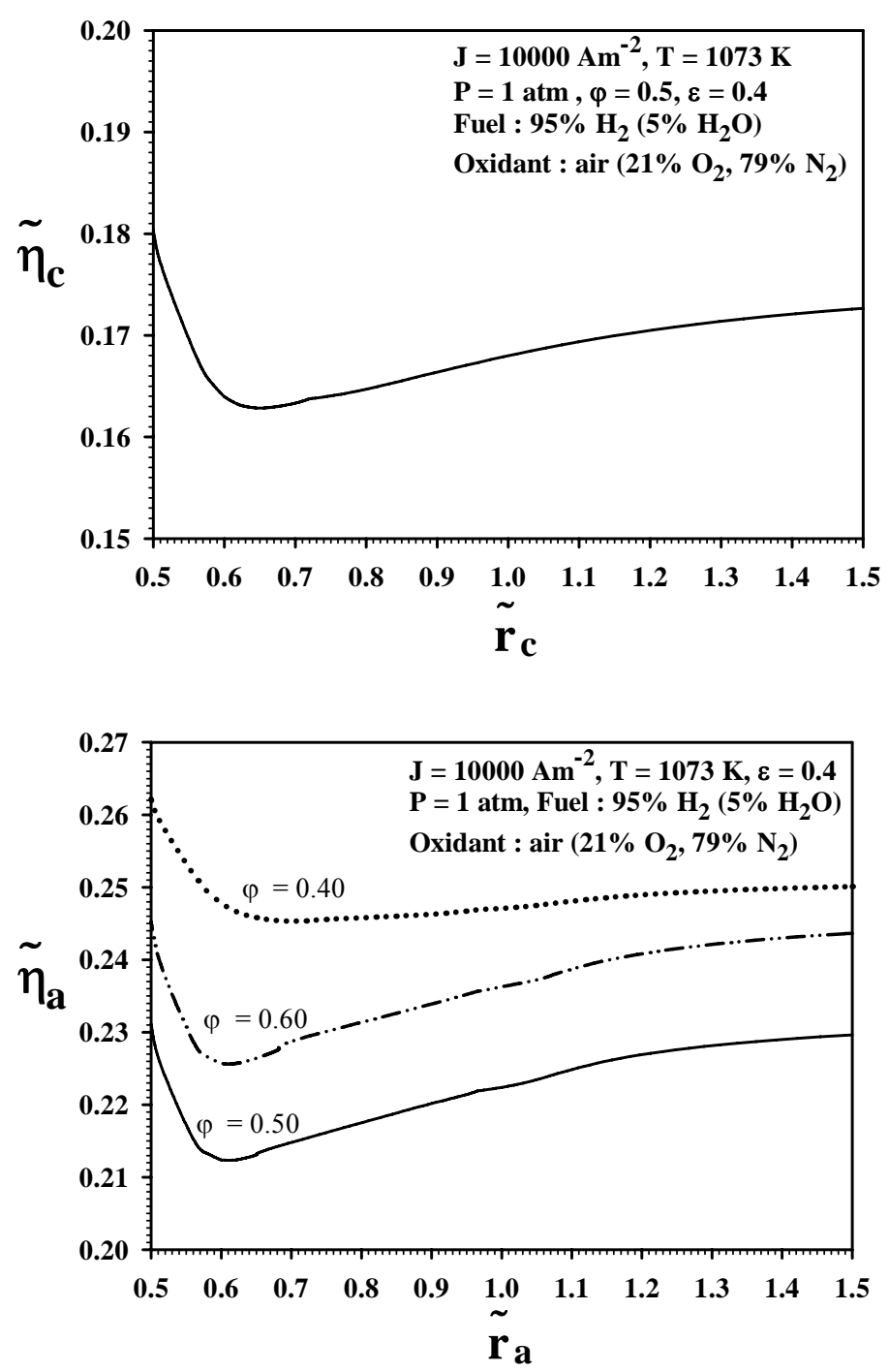
Figure 8.

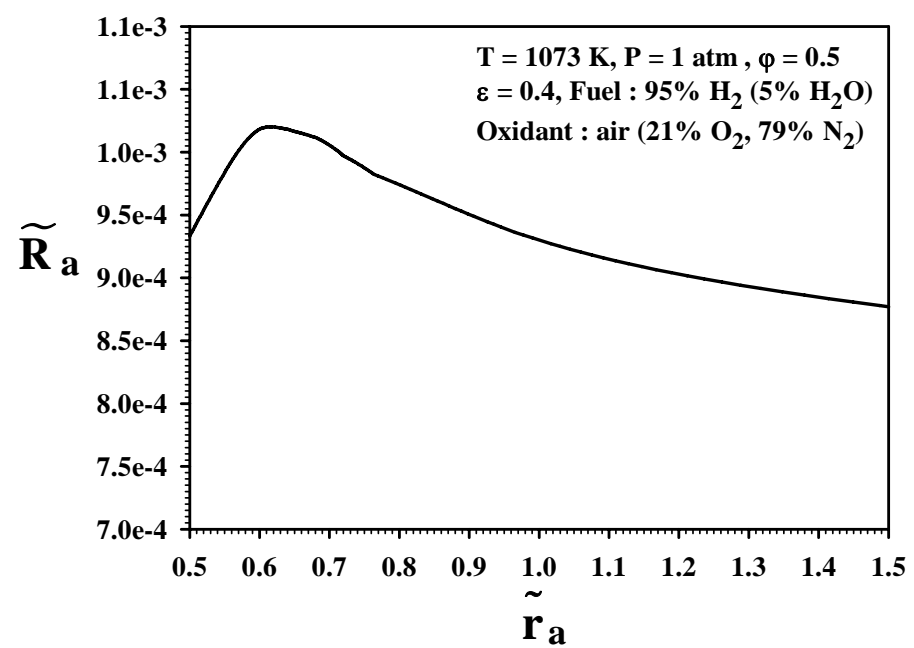

Figure 9.

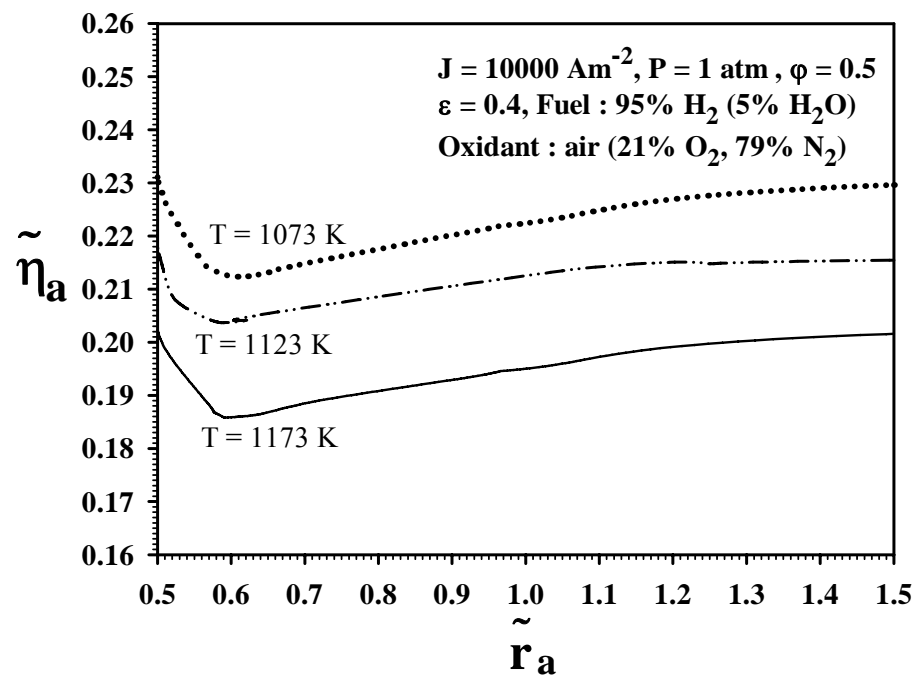

Figure 10.

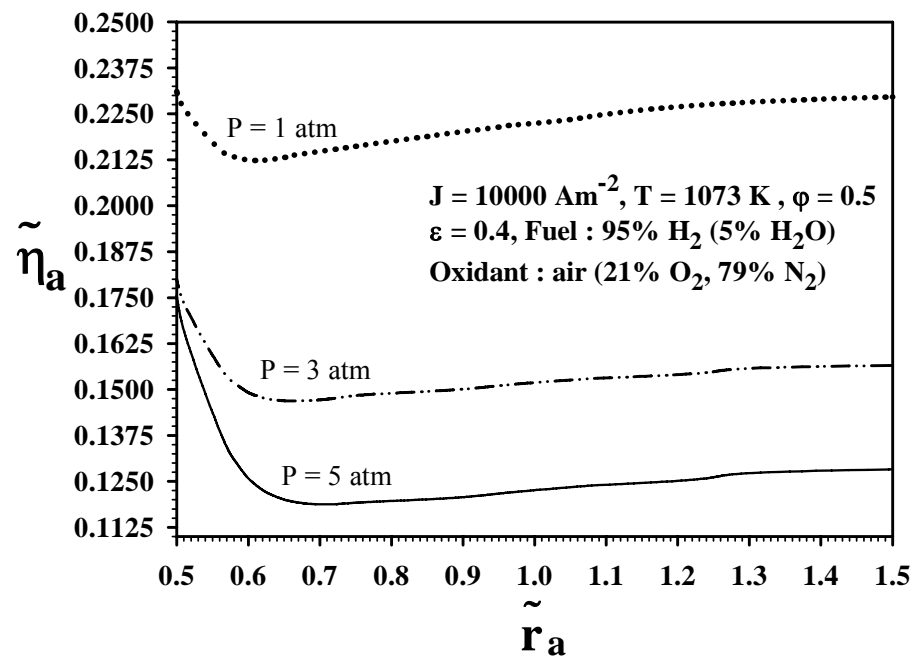

